\title{
Symmetry and the Role of the Anion Sublattice in Aurivillius Oxyfluoride $\mathrm{Bi}_{2} \mathrm{TiO}_{4} \mathrm{~F}_{2}$
}

\author{
Andrew T. Giddings, Euan A. S. Scott, Martin C. Stennett, David C. Apperley, Colin Greaves, \\ Neil C. Hyatt,* and Emma E. McCabe*
}

Cite This: Inorg. Chem. 2021, 60, 14105-14115

Read Online

ABSTRACT: The photocatalytic and dielectric behaviors of Aurivillius oxyfluorides such as $\mathrm{Bi}_{2} \mathrm{TiO}_{4} \mathrm{~F}_{2}$ depend sensitively on their crystal structure and symmetry but these are not fully understood. Our experimental work combined with symmetry analysis demonstrates the factors that influence anion order and how this might be tuned to break inversion symmetry. We explore an experimental approach to explore anion order, which combines Rietveld analysis with strain analysis.

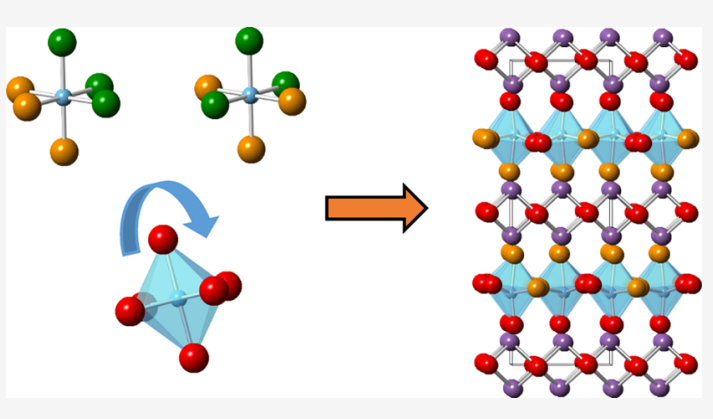

\section{INTRODUCTION}

The renewed interest in mixed anion materials, containing two or more anions, results from both their increased compositional degrees of freedom as well as the opportunity to use anion order to tune the electronic structure, symmetry, and related properties. ${ }^{1-5}$ These "designer materials" ${ }^{6}$ include photocatalysts, ${ }^{7,8}$ magnetic, ${ }^{9,10}$ superconducting, ${ }^{11}$ and nonlinear optical materials, ${ }^{12,13}$ and ferroelectrics. ${ }^{14}$ These properties are acutely sensitive to structural features, including the anion sublattice, and so it is crucial to understand anion ordering and the factors that influence it as well as how to characterize it when it arises.

Oxyfluorides, containing both oxide $\mathrm{O}^{2-}$ and fluoride $\mathrm{F}^{-}$ ions, illustrate these challenges. Topotactic fluorination reactions of layered oxides ${ }^{15,16}$ typically result in oxyfluorides with $\mathrm{F}^{-}$occupation of (otherwise vacant) interstitial sites, which is often accompanied by occupation of one or two anion sites in an ordered fashion. These reactions have been powerful for tuning properties including magnetism, superconductivity, and properties associated with the lack of inversion symmetry. ${ }^{10,11,17}$ However, the similar sizes of $\mathrm{O}^{2-}$ and $\mathrm{F}^{-}$ ions ${ }^{18}$ mean that single-step solid-state reactions (forming the oxyfluoride directly from oxide and fluoride reagents, often at high temperatures) can result in a lack of long-range order of $\mathrm{O}^{2-}$ and $\mathrm{F}^{-}$ions over the anion sites. ${ }^{19}$ The similar X-ray and neutron scattering lengths of $\mathrm{O}^{2-}$ and $\mathrm{F}^{-}$ions ${ }^{20}$ make exploring this anion order (whether it is long-range or shortrange) particularly challenging. ${ }^{21}$ Theory work highlighting the opportunity to control the symmetry (and therefore properties) using the anion order ${ }^{4}$ has motivated further work on these systems.
Aurivillius materials, a class of layered perovskite-related materials, have long been known for their ferroelectric properties. $^{22,23}$ They have a general formula $\mathrm{Bi}_{2} A_{n-1} B_{n} X_{3 n+3}$ ( $X$ is an oxide or halide ion) and adopt structures based on fluorite-like $\left[\mathrm{Bi}_{2} \mathrm{O}_{2}\right]^{2+}$ layers separated by blocks of cornerlinked $\mathrm{BX}_{6}$ octahedra, which are $n$ layers thick, Figure 1 . The $n$ $=1$ phases $\mathrm{Bi}_{2} \mathrm{WO}_{6}$ and $\mathrm{Bi}_{2} \mathrm{MoO}_{6}$ are perhaps illustrative of many features of this family, adopting polar structures (of $P 2_{1} a b$ symmetry) at low temperatures, with rotations of $\mathrm{BO}_{6}$ octahedra about both the long (out-of-plane) axis and about an in-plane axis, with polar displacements of $B$ cations toward the edge of the octahedra. ${ }^{24-29}$ On warming, they undergo a phase transition to a second polar phase of $B 2 c b$ symmetry (in which rotations about the long axis are frozen out) before more complex phase transitions occur above their ferroelectric $T_{\mathrm{C}}{ }^{30-32}$ In addition to their ferroelectric behavior, both are effective photocatalysts, particularly in nanostructured forms. $^{33-36}$

The $n=1$ Aurivillius oxyfluorides $\mathrm{Bi}_{2} \mathrm{NbO}_{5} \mathrm{~F}$ and $\mathrm{Bi}_{2} \mathrm{TaO}_{5} \mathrm{~F}^{37} \mathrm{Bi}_{2} \mathrm{VO}_{5} \mathrm{~F}^{38} \mathrm{Bi}_{2} \mathrm{TiO}_{4} \mathrm{~F}_{2}{ }^{39}$ and $\mathrm{Bi}_{2} \mathrm{CoO}_{2} \mathrm{~F}_{4}{ }^{40}$ are less well understood but are increasingly attracting attention for their photocatalytic behavior, ${ }^{41-44}$ and this is thought to be influenced by their polar and dielectric properties. ${ }^{45}$ However, the dielectric behavior of $\mathrm{Bi}_{2} \mathrm{TiO}_{4} \mathrm{~F}_{2}$ is still not fully understood: it was first considered as a ferroelectric ${ }^{46,47}$ with

Received: May 18, 2021

Published: September 1, 2021 


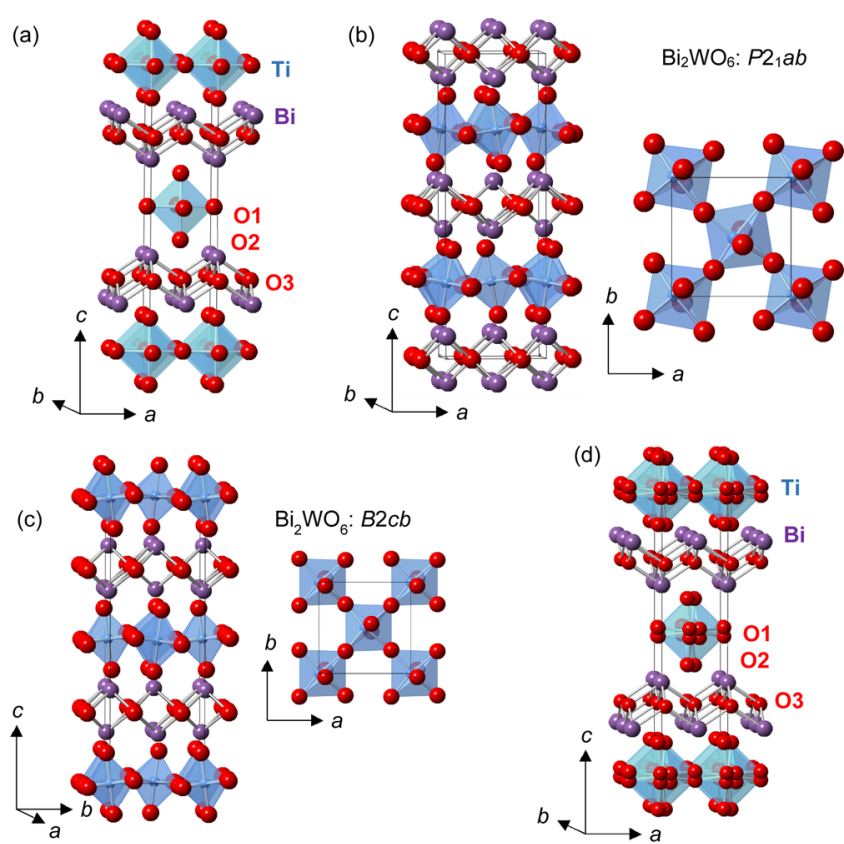

Figure 1. Illustration of (a) ideal ordered $I 4 / \mathrm{mmm}$ structure for an $n$ $=1$ Aurivillius phase; (b) low-temperature $P 2_{1} a b$ phase for $\mathrm{Bi}_{2} \mathrm{WO}_{6}$ and (c) intermediate $\mathrm{B2} c \mathrm{cb}$ phase for $\mathrm{Bi}_{2} \mathrm{WO}_{6} ;{ }^{30}$ (d) disordered I4/ mmm structure of $\mathrm{Bi}_{2} \mathrm{TiO}_{4} \mathrm{~F}_{2}$ (with displacive disorder of equatorial and apical anion positions to $16 \mathrm{n}$ and $16 \mathrm{~m}$ sites, respectively) from $100 \mathrm{~K}$ NPD Rietveld refinement; $\mathrm{TiX}_{6}$ or $\mathrm{WO}_{6}$ polyhedra, $\mathrm{Bi}$, and $\mathrm{O}$ are shown in blue, purple, and red, respectively.

a ferroelectric Curie temperature $T_{\mathrm{C}}=284 \mathrm{~K},{ }^{47}$ but later, experimental work on bulk ceramic samples found no evidence of ferroelectricity or of a polar crystal structure. ${ }^{39}$ Interestingly, studies on thin films of $\mathrm{Bi}_{2} \mathrm{TiO}_{4} \mathrm{~F}_{2}$ suggest a $T_{\mathrm{C}}$ of $240 \mathrm{~K}^{48}$ These ambiguities in the literature suggest some sample dependence of properties (and therefore structure and symmetry) that may be sensitive to synthesis routes, cooling rates, and strain. This sensitivity may result from the complexity of the anion sublattice-both in terms of the distribution of $\mathrm{O}^{2-}$ and $\mathrm{F}^{-}$ions over the anion sites and any displacive disorder of the anion positions. It is timely to reconsider these materials and, in particular, the anion ordering possibilities and their consequences for symmetry and polar properties. $^{49}$ Our experimental work (based on property measurements as well as neutron powder diffraction (NPD) and electron diffraction) is consistent with earlier studies, ${ }^{39}$ and our symmetry analysis demonstrates that it is possible to break inversion symmetry in these systems by ordering of $\mathrm{O}^{2-}$ and $\mathrm{F}^{-}$ions over the anion sites and in combination with octahedral rotations. We explore an experimental method that may be applied more widely to investigate anion order in oxyfluorides based on the Rietveld method combined with global instability index (GII) calculations to introduce structural strain information into structural refinements.

\section{METHODS}

Synthesis of $\mathrm{Bi}_{2} \mathrm{TiO}_{4} \mathrm{~F}_{2}$ was achieved by solid-state reaction of a stoichiometric ratio of $\mathrm{BiF}_{3}, \mathrm{Bi}_{2} \mathrm{O}_{3}$, and $\mathrm{TiO}_{2}$. An intimate mixture of reagents was pressed into several $8 \mathrm{~mm}$ diameter pellets, which were wrapped in Pt foil and sealed in a quartz tube, together with a separate $0.2 \mathrm{~mol}$ excess of $\mathrm{BiF}_{3}$, also wrapped in $\mathrm{Pt}$ foil (to compensate for $\mathrm{BiF}_{3}$ volatilization). Samples were reacted three times at $640{ }^{\circ} \mathrm{C}$ for $48 \mathrm{~h}$, with a $2{ }^{\circ} \mathrm{C} \mathrm{min}^{-1}$ ramp rate; pellets were recovered after each reaction and ground to a fine powder, prior to forming new green pellets for the subsequent reaction. By using this method, it was found possible to produce sintered bodies of $\sim 82 \%$ theoretical density. Herein, we report results from three sample preparations:

- Sample A: determined to comprise $95.5(1) \% \mathrm{Bi}_{2} \mathrm{TiO}_{4} \mathrm{~F}_{2}$ and $4.5(1) \%$ BiOF by weight, according to Rietveld analysis of Xray and neutron diffraction data (see below). This material was used for acquisition of X-ray, neutron, and electron diffraction data and electrical property measurements.

- Sample B was single-phase $\mathrm{Bi}_{2} \mathrm{TiO}_{4} \mathrm{~F}_{2}$ within the limit of sensitivity of powder X-ray diffraction data.

- Sample C: determined to comprise $88.8(5) \% \mathrm{Bi}_{2} \mathrm{TiO}_{4} \mathrm{~F}_{2}$ and $11.2(5) \%$ BiOF by weight but with evidence of a further trace of an unidentified impurity phase(s) according to Rietveld analysis of powder X-ray diffraction data.

Electrical measurements were performed on sintered pellets (Sample A), with sputtered gold electrodes, using an HP 4192A impedance analyzer with a $\mathrm{He}$ cryocooler (Oxford instruments Model CC1.5). Data were corrected for sample geometry prior to analysis. Elemental analysis was performed using a CAMECA SX51 WDSEPMA; the sintered specimens were embedded in a cold setting epoxy resin and polished to a finish of $0.25 \mu \mathrm{m}$ diamond paste prior to analysis. Fluorine determination was performed using an F-selective electrode after fusion with $\mathrm{Na}_{2} \mathrm{CO}_{3} / \mathrm{K}_{2} \mathrm{CO}_{3}$ and acid digestion.

Variable temperature time-of-flight NPD data were acquired using the high-resolution powder diffractometer HRPD at the ISIS Neutron and Muon Source (Chilton, UK). A 7 g sample was contained in a vanadium can, mounted within a cryostat (Sample A). For the purpose of structure refinement, data collection times were $\sim 4 \mathrm{~h}$ at 300,260 , and $175 \mathrm{~K}$ and $\sim 8 \mathrm{~h}$ at $100 \mathrm{~K}$. The diffraction data were normalized to the incident beam spectrum and corrected for detector efficiency (using a vanadium standard) and sample attenuation. Rietveld refinements were carried out using the GSAS suite of programs $^{50,51}$ and TopasAcademic ${ }^{52,53}$ using NPD data from both the high-resolution back scattering detectors (Bank $1: 2 \theta \approx 168^{\circ}, \Delta d / d=$ $5 \times 10^{-4}$ ) and moderate-resolution transverse detectors (Bank 2: $2 \theta$ $\left.\approx 90^{\circ}, \Delta d / d=2 \times 10^{-3}\right)$.

MAS NMR experiments were performed at $300 \mathrm{~K}$, using a Varian Unity Inova spectrometer operating at $282.09 \mathrm{MHz}$ for ${ }^{19} \mathrm{~F}$ (Samples $\mathrm{B}$ and $\mathrm{C}$ ). The experimental parameters were acquisition time $25 \mathrm{~ms}$, recycle delay $5 \mathrm{~s}$, and spectral width $200 \mathrm{kHz}$. Chemical shifts were referenced with respect to the signal from $\mathrm{CFCl}_{3}$ at $d=0.00 \mathrm{ppm}$.

\section{RESULTS}

3.1. Synthesis and Preliminary Analysis. Rietveld refinement using room temperature XRPD data of Sample A was consistent with the formation of an $n=1$ Aurivillius phase and was fitted with a main phase of $I 4 / \mathrm{mmm}$ symmetry for $\mathrm{Bi}_{2} \mathrm{TiO}_{4} \mathrm{~F}_{2}(95.5(1) \%$ by weight) and a trace of $\mathrm{BiOF}(4.5(1) \%$ by weight) (see Supporting Information). Elemental analysis by EPMA gave a composition of $\mathrm{Bi}_{1.98(2)} \mathrm{Ti}_{1.04(2)} \mathrm{O}_{4} \mathrm{~F}_{2.1(1)}$ for Sample A, in good agreement with the target stoichiometry, which is assumed in the subsequent analysis. Electron diffraction data from Sample A were collected at $\sim 300 \mathrm{~K}$ and at $\sim 100 \mathrm{~K}$, and again, indexed reflections were consistent with the aristotype $I 4 / \mathrm{mmm}$ model (see Supporting Information). Diffraction patterns taken down the [100] zone axis were indexed using this high-symmetry unit cell, and no additional reflections (or diffuse scattering) were observed. However, further zone axes (e.g. [110] and [001]) would be needed to rule out the possibility of orthorhombic distortions as observed, for example, for $\mathrm{Bi}_{2} \mathrm{NbO}_{5} \mathrm{~F} .{ }^{54}$

3.2. Property Measurements. The sintered pellets of $\mathrm{Bi}_{2} \mathrm{TiO}_{4} \mathrm{~F}_{2}$ were highly insulating at room temperature and below. The relative permittivity of $\mathrm{Bi}_{2} \mathrm{TiO}_{4} \mathrm{~F}_{2}$ was measured at $10 \mathrm{kHz}$ to $1 \mathrm{MHz}$, on pellets of $\sim 85 \%$ theoretical density, prepared from Sample A $\left(95.5(1) \% \mathrm{Bi}_{2} \mathrm{TiO}_{4} \mathrm{~F}_{2}\right.$ and $4.5(1) \%$ 
BiOF by weight). The relative permittivity was found to be essentially temperature and frequency independent between 10 and $320 \mathrm{~K}$, and there is no evidence for a dielectric anomaly in this temperature range (Figure 2). This contrasts with the report of a paraelectric-ferroelectric phase transition in $\mathrm{Bi}_{2} \mathrm{TiO}_{4} \mathrm{~F}_{2}$ at $T_{\mathrm{C}}=284 \mathrm{~K}$ by Ismailzade and Ravez. ${ }^{47}$

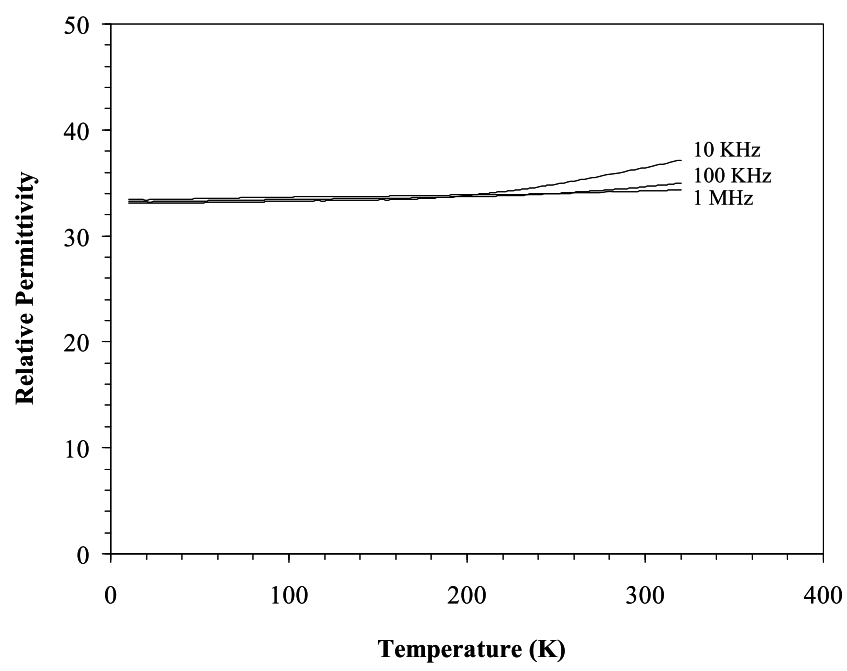

Figure 2. Temperature and frequency dependence of relative permittivity of $\mathrm{Bi}_{2} \mathrm{TiO}_{4} \mathrm{~F}_{2}$ measured between $10 \mathrm{kHz}$ and $1 \mathrm{MHz}$.

3.3. ${ }^{19} \mathrm{~F}$ Magic Angle Spinning Solid-State NMR. ${ }^{19} \mathrm{~F}$ magic angle spinning solid-state nuclear magnetic resonance $\left({ }^{19} \mathrm{~F}\right.$ MAS ssNMR) data were collected for two samples of $\mathrm{Bi}_{2} \mathrm{TiO}_{4} \mathrm{~F}_{2}$ :

- Sample B was single phase within the limit of sensitivity of XRPD.

- Sample C contained 11.2(5)\% BiOF by weight and a further unidentified impurity phase as determined from Rietveld analysis of XRPD data.

The spectra from both samples were essentially identical, with a single broad band centered at approximately $-54 \mathrm{ppm}$ and associated spinning side bands centered at approximately 0 and $-105 \mathrm{ppm}$, as shown in Figure 3. These spectra are very similar in appearance to the ${ }^{19} \mathrm{~F}$ NMR spectrum of $\mathrm{Bi}_{2} \mathrm{TiO}_{4} \mathrm{~F}_{2}$ reported by Needs et al. ${ }^{39}$

The broad line width of the ${ }^{19} \mathrm{~F}$ MAS NMR signals could arise from one or more causes, including

(i) Homonuclear $\left({ }^{19} \mathrm{~F},{ }^{19} \mathrm{~F}\right)$ dipolar coupling between $\mathrm{F}$ atoms in close proximity.

(ii) Heteronuclear coupling, for example, between ${ }^{19} \mathrm{~F}$ and quadrupolar ${ }^{209} \mathrm{Bi}$ (100\% natural abundance).

(iii) Static and/or dynamic disorder of ${ }^{19} \mathrm{~F}$ atoms over the available anion sites.

Heteronuclear dipolar coupling effects were considered too small to give rise to the observed broad line widths previously observed in $\mathrm{Bi}_{2} \mathrm{TiO}_{4} \mathrm{~F}_{2}$ and $\mathrm{Bi}_{2} \mathrm{NbO}_{5} \mathrm{~F},{ }^{39}$ although we cannot rule out some coupling between bismuth and $\mathrm{F}$ in the apical $X 2$ site. This suggests that disorder of the anion sublattice, principally displacive disorder of the anion sites, (and disorder of $\mathrm{F}^{-} / \mathrm{O}^{2-}$ over the available sites to a lesser extent) is a cause of the broad line shape. Needs et al. presented ${ }^{19} \mathrm{~F}$ MAS NMR for both $\mathrm{Bi}_{2} \mathrm{NbO}_{5} \mathrm{~F}$ (with most likely only one $\mathrm{F}^{-}$per $\mathrm{NbX}_{6}$ polyhedron) and $\mathrm{Bi}_{2} \mathrm{TiO}_{4} \mathrm{~F}_{2}$ (with two $\mathrm{F}^{-}$per $\mathrm{TiX} 6$ polyhedron), and it is striking that the spectrum for $\mathrm{Bi}_{2} \mathrm{NbO}_{5} \mathrm{~F}$

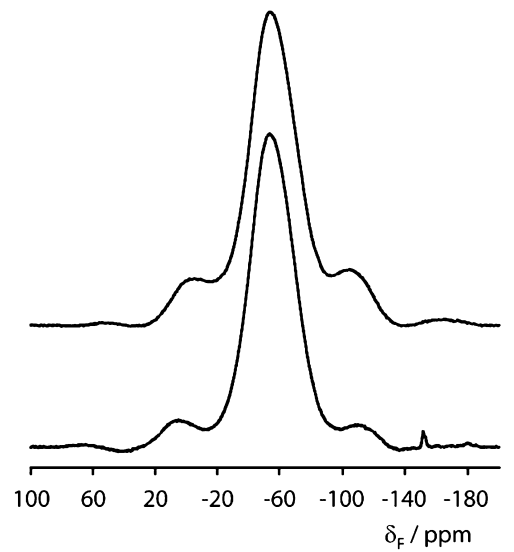

Figure 3. ${ }^{19} \mathrm{~F}$ MAS NMR spectra of two specimens of $\mathrm{Bi}_{2} \mathrm{TiO}_{4} \mathrm{~F}_{2}$; Sample B, lower, was determined to be single phase, within the limit of sensitivity of powder X-ray diffraction. Sample C, upper, contained an impurity of $11.2(5)$ wt $\% \mathrm{BiOF}$ plus an additional unidentified phase. The spin rate was $16.3 \mathrm{KHz}$, with 200 free induction decays for Sample A and 248 for Sample B.

is at least as broad as that observed for $\mathrm{Bi}_{2} \mathrm{TiO}_{4} \mathrm{~F}_{2} \cdot{ }^{39}$ This could indicate that the displacive disorder of the anion sites (e.g. displacement of the equatorial and apical sites off their high symmetry $4 \mathrm{c}$ and $4 \mathrm{e}$ sites in the $14 / \mathrm{mmm}$ model to $16 \mathrm{n}$ and $16 \mathrm{~m}$, respectively, as discussed below) may be sufficient to explain the broadened signal. We cannot rule out $\mathrm{F}^{-}$ occupancy of more than one site (e.g. partial occupancy of equatorial and apical sites) which could also give rise to some broadening of the signal. It is noted that the signal from Sample B is broader than that from Sample C (when measured at the same spin rate). This suggests that the fluorine atoms are more strongly coupled, that is, on average, closer together, in Sample B compared to Sample C. This could suggest that antisite disorder (i.e. $\mathrm{F}^{-}$occupancy of equatorial and apical sites), which is likely to depend on the preparation method and thermal history, could also play a role in broadening the NMR signal. (In the case of Sample C, changing the spin rate from 14.0 to $16.3 \mathrm{kHz}$ resulted in some narrowing of the signal, suggesting that homonuclear coupling is at least partly responsible for the broad line shape.) There are relatively few ${ }^{19} \mathrm{~F}$ NMR studies on titanium oxyfluorides, making it difficult to compare the chemical shift observed here with typical shifts for terminal and bridging fluoride sites in $\mathrm{Ti}(\mathrm{O}, \mathrm{F})_{6}$ octahedra. The presence of a $\mathrm{BiOF}$ impurity in Sample C (noted from analysis of powder diffraction data) means that $\sim 13 \%$ of the fluoride content is in this $\mathrm{BiOF}$ impurity phase, in which it occupies a bonding position very similar to the apical $X 2$ site in $\mathrm{Bi}_{2} \mathrm{TiO}_{4} \mathrm{~F}_{2}$. This particular BiOF environment does not give rise to an apparently distinctive signal in our ${ }^{19} \mathrm{~F}$ MAS NMR data above presumably because it coincides with the main resonance.

3.4. Structural Analysis Using Neutron Powder Diffraction Data. 3.4.1. Rietveld Refinements and the Average Structure. NPD data were collected at $100 \mathrm{~K}$ and at $300 \mathrm{~K}$ (i.e. below and above the reported $T_{\mathrm{C}}$ of $284 \mathrm{~K}^{47}$ ) to investigate possible structural changes within this temperature range; this study utilized Sample A which was also characterized by X-ray and electron diffraction (Section 3.1) and electrical measurements (Section 3.2). No attempt was made to distinguish between oxygen and fluorine sites due to their similar neutron scattering lengths (5.803 and $5.654 \mathrm{fm}$ for 
Table 1. Details from Rietveld Refinements Using NPD Data and the Disordered Model of $\mathrm{I4} / \mathrm{mmm}_{\mathrm{Symmetry}}$ for $\mathrm{Bi}_{2} \mathrm{TiO}_{4} \mathrm{~F}_{2}$ (with Displacive Disorder of Equatorial and Apical Anion Positions to $16 \mathrm{n}$ and $16 \mathrm{~m}$ Sites, Respectively) and Selected Bond Lengths and Angles

\begin{tabular}{|c|c|c|c|c|c|}
\hline & & $100 \mathrm{~K}$ & $175 \mathrm{~K}$ & $260 \mathrm{~K}$ & $300 \mathrm{~K}$ \\
\hline$R_{\mathrm{wp}}(\%)$ & & 5.67 & 4.73 & 4.66 & 4.34 \\
\hline$R_{\mathrm{p}}(\%)$ & & 5.56 & 4.32 & 4.16 & 3.97 \\
\hline$a(\AA)$ & & $3.80050(6)$ & $3.80313(4)$ & $3.80705(4)$ & $3.80922(4)$ \\
\hline$c(\AA)$ & & $16.2990(3)$ & $16.3105(2)$ & $16.3247(2)$ & $16.3328(2)$ \\
\hline volume $\left(\AA^{3}\right)$ & & $235.419(9)$ & $235.913(6)$ & $236.604(6)$ & $236.991(6)$ \\
\hline \multirow[t]{2}{*}{$\mathrm{Bi}(4 e)$} & $z$ & $0.32815(7)$ & $0.32830(6)$ & $0.32825(7)$ & $0.32820(6)$ \\
\hline & $U_{\text {iso }} \times 100\left(\AA^{2}\right)$ & $1.4(1)$ & $1.61(7)$ & $1.83(7)$ & $2.08(7)$ \\
\hline $\mathrm{Ti}(2 a)$ & $U_{\text {iso }} \times 100\left(\AA^{2}\right)$ & $2.4(1)$ & $2.4(1)$ & $2.7(1)$ & $3.0(1)$ \\
\hline \multirow[t]{3}{*}{$X 1(16 n)$} & $x$ & $0.0706(9)$ & $0.0699(7)$ & $0.0685(8)$ & $0.0665(8)$ \\
\hline & $z$ & $0.0154(2)$ & $0.0160(2)$ & $0.0160(2)$ & $0.0163(2)$ \\
\hline & $U_{\text {iso }} \times 100\left(\AA^{2}\right)$ & $1.2(1)$ & $1.3(1)$ & $1.5(1)$ & $1.7(1)$ \\
\hline \multirow[t]{3}{*}{$X 2(16 m)$} & $x$ & $0.051(1)$ & $0.0505(9)$ & $0.0491(9)$ & $0.0515(8)$ \\
\hline & $z$ & $0.1166(1)$ & $0.1166(1)$ & $0.1166(1)$ & $0.1165(1)$ \\
\hline & $U_{\text {iso }} \times 100\left(\AA^{2}\right)$ & $1.6(1)$ & $2.2(1)$ & $2.4(1)$ & $2.4(1)$ \\
\hline$X 3(4 d)$ & $U_{\text {iso }} \times 100\left(\AA^{2}\right)$ & $0.82(9)$ & $1.06(6)$ & $1.20(7)$ & $1.39(7)$ \\
\hline $\mathrm{Bi}-X 2(\AA)$ & & $1 \times 2.574(5)$ & $1 \times 2.579(5)$ & $1 \times 2.589(5)$ & $1 \times 2.580(4)$ \\
\hline $\mathrm{Bi}-\mathrm{X} 2(\AA)$ & & $2 \times 2.848(1)$ & $2 \times 2.8486(9)$ & $2 \times 2.8510(9)$ & $2 \times 2.8545(9)$ \\
\hline $\mathrm{Bi}-X 2(\AA)$ & & $1 \times 3.097(5)$ & $1 \times 3.095(5)$ & $1 \times 3.090(5)$ & $1 \times 3.105(5)$ \\
\hline $\mathrm{Bi}-X 3(\AA)$ & & $4 \times 2.2876(7)$ & $4 \times 2.2906(6)$ & $4 \times 2.2924(6)$ & $4 \times 2.2932(6)$ \\
\hline $\mathrm{Ti}-X 1(\AA)$ & & $4 \times 1.9355(9)$ & $4 \times 1.9377(7)$ & $4 \times 1.9389(8)$ & $4 \times 1.9396(7)$ \\
\hline $\mathrm{Ti}-X 2(\AA)$ & & $2 \times 1.920(5)$ & $2 \times 1.921(2)$ & $2 \times 1.921(2)$ & $2 \times 1.923(2)$ \\
\hline
\end{tabular}
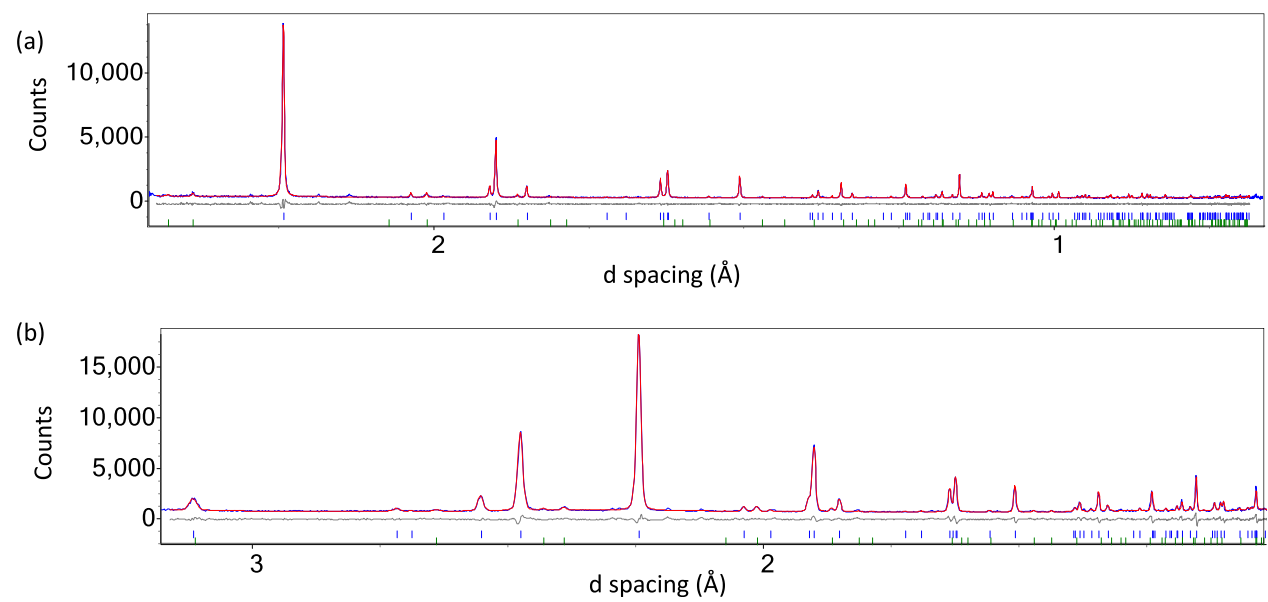

Figure 4. Rietveld refinement profiles using $100 \mathrm{~K}$ NPD data and the disordered model of $I 4 / m m m$ symmetry for $\mathrm{Bi}_{2} \mathrm{TiO}_{4} \mathrm{~F}_{2}$ (with displacive disorder of equatorial and apical anion positions to $16 \mathrm{n}$ and $16 \mathrm{~m}$ sites, respectively) with the upper (blue) ticks showing peak positions for the main phase $\left(96.1(3) \%\right.$ by weight) and the lower (green) ticks showing peak positions for the BiOF impurity $\left(3.9(3) \%\right.$ by weight); $R_{\mathrm{wp}}=6.39 \%$ and $R_{\mathrm{p}}=$ 5.85\% (55 parameters). The upper panel (a) shows data from the backscattered band and the lower panel (b) shows data from the $90^{\circ}$ bank. Observed, calculated, and difference profiles are shown in blue, red, and grey, respectively.

oxygen and fluorine, respectively), ${ }^{20}$ and all anion sites were modeled as occupied by oxygen. Data collected at all temperatures were qualitatively similar with the main peaks consistent with the aristotype model of $14 / \mathrm{mmm}$ symmetry for an $n=1$ Aurivillius phase. Several additional very weak reflections were also observed, some of which were fitted by traces of $\mathrm{BiOF}(\sim 4 \%)$, consistent with lab XRPD analysis. Attempts to include other impurity phases (such as $\mathrm{TiO}_{2}$, $\mathrm{Bi}_{2} \mathrm{O}_{3}, \mathrm{BiF}_{3}, \mathrm{Bi}_{3} \mathrm{Ti}_{2} \mathrm{O}_{8} \mathrm{~F}$, and $\mathrm{Bi}_{7} \mathrm{~F}_{11} \mathrm{O}_{5}$ ) to fit other peaks were unsuccessful.

Rietveld refinement at $100 \mathrm{~K}$ using a model of $14 / \mathrm{mmm}$ symmetry gives unfeasibly large atomic displacement parameters (ADPs) for the equatorial anion site $X 1$ (and, to a lesser extent, the apical anion site $X 2),\left(5.6(1) \times 100 \AA^{2}\right.$ and 3.7(1) $\times 100 \AA^{2}$, respectively; see Supporting Information). Allowing these ADPs to refine anisotropically revealed significant displacements (either static or dynamic) of $X 1$ along [100] (consistent with rotation of $\mathrm{TiX}_{6}$ octahedra about [001]) and along [001] (consistent with rotation about an in-plane axis), similar to the displacive disorder observed in related systems. ${ }^{55,56}$ Moving the equatorial and apical anions to lower symmetry sites ( $X 1$ from $4 c$ to $16 n$ and $X 2$ from $4 e$ to $16 \mathrm{~m})$ gave more reasonable $\mathrm{ADPs}\left(1.2(1) \times 100 \AA^{2}\right.$ and $0.82(9) \times 100 \AA^{2}$, respectively) and an improvement in fit $\left[R_{\mathrm{wp}}\right.$ decreased from $6.95 \%$ ( 52 parameters) for the ordered model to $5.67 \%$ ( 55 parameters) for the displacive disordered model]. Refinement details and selected bond lengths are given in Table 1 and refinement profiles in Figure 4, and the disordered 
structural model of $I 4 / \mathrm{mmm}$ symmetry is illustrated in Figure 1d. ADPs were not refined anisotropically for this displacively disordered model.

Similar models were used for Rietveld refinements using 175 $\mathrm{K}, 260 \mathrm{~K}$, and $300 \mathrm{~K} \mathrm{NPD}$ data and showed little change within this temperature range. The $X 1$ and $X 2$ sites again had unusually large $\mathrm{ADPs}$ for the ordered $I 4 / \mathrm{mmm}$ model $\left(U_{\text {iso }}\right.$ values for $X 1$ and $X 2$ sites of 5.8(1) $\times 100 \AA^{2}$ and $4.0(1) \times 100$ $\AA^{2}$ at $175 \mathrm{~K}, 6.0(1) \times 100 \AA^{2}$ and $4.1(1) \times 100 \AA^{2}$ at $260 \mathrm{~K}$, and $5.9(1) \times 100 \AA^{2}$ and $4.2(1) \times 100 \AA^{2}$ at $300 \mathrm{~K}$, respectively). There is relatively little temperature dependence in these values, which may indicate a static (displacive) disorder rather than a dynamic disorder. The disordered models of $I 4 / \mathrm{mmm}$ symmetry gave more reasonable ADPs and are most appropriate to describe the long-range structure within this temperature range (Table 1 ).

The high ADPs may indicate local/short-range distortions reflected by our disordered $14 / \mathrm{mmm}$ model (i.e. with displacive disorder of the equatorial and apical anion sites) or could indicate that rotations of the $\mathrm{Ti} X_{6}$ octahedra are coherent over longer length scales and give an average structure of lower symmetry. It can be helpful to consider possible lower symmetry structures in terms of the high-symmetry parent structure with symmetry-lowering distortions (described by an irreducible representation or irrep) imposed on it. ${ }^{57,58}$ Common distortions in $n=1$ Ruddlesden-Popper and Aurivillius phases include rotations of the $B X_{6}$ octahedra. These rotations can be about the long axis of the unit cell described by the $\mathrm{X}_{2}^{+}$irrep (or $a^{0} a^{0} c^{ \pm}$rotations in Glazer notation or $00 \theta 00 \theta$ in Aleksandrov's notation) or about an inplane axis such as the $\mathrm{X}_{3}^{+}$rotations $\left(a^{-} a^{-} c^{0}\right.$ in Glazer notation or $\Phi \Phi 0 \Phi \Phi 0$ in Aleksandrov's notation). (We have used the $c^{ \pm}$notation to indicate rotation of the $B X_{6}$ octahedra about the $c$ axis, but we cannot define the direction of rotation with respect to other perovskite-like layers in the block because these are single-layer materials.) These have been explored and tabulated $^{59,60}$ and are explained in more detail in the Supporting Information. Aurivillius materials are well known for their polar and ferroelectric behavior, and this often results from in-plane polar displacements (along [100] or [110] of the high symmetry unit cell) of cations relative to anions described by the $\Gamma_{5}{ }^{-}$irrep. ${ }^{27-29}$ It is also possible to have an out-of-plane polarization (along the long axis of the unit cell) described by the $\Gamma_{3}{ }^{-}$irrep. (The same irrep language can also be used to describe anion ordering arrangements, as explored in Section 4.2.) ISODISTORT ${ }^{57,38}$ was used to explore likely structural rotations including rotations of the $\mathrm{Ti}_{6}$ octahedra $^{59,60}$ and inplane displacements (see Supporting Information). Larger, orthorhombic unit cells could index one or two additional weak reflections (e.g. $\sqrt{ } 2 a \times \sqrt{ } 2 a \times c$ cells index a peak at $\sim 2.14 \AA$ as $(107) ; 2 a \times 2 a \times c$ cells index a peak at $\sim 2.30 \AA$ as (303); see Supporting Information) and so lower symmetry models with larger unit cells were considered. Mode inclusion analysis $^{61,62}$ suggested that the greatest improvement in fit was observed for models allowing in-plane polar displacements (described by the $\Gamma_{5}^{-}$irrep; see above and Supporting Information), but polar models did not fit the intensity to the superstructure peaks and often still gave high ADPs. Although an exhaustive search was made to find a lower symmetry model to give a significantly better fit than this disordered $14 / \mathrm{mmm}$ model, the search was unsuccessful: models did not give intensity to additional reflections and/or intensity was predicted where none was observed. Care was also taken to consider models of $P b c a$ and $P c a 2_{1}$ symmetries (as reported for $\mathrm{Bi}_{2} \mathrm{NbO}_{5} \mathrm{~F}^{54}$ or $\mathrm{Bi}_{2} \mathrm{WO}_{6}{ }^{24,28,30}$ ), but the fits from these models were no better than that from the disordered $14 / \mathrm{mmm}$ model, and suggested high ADPs for equatorial (and apical) anion sites. No broadening of $h$ h 0 or $\mathrm{hhl}$ reflections (indexed with respect to the $14 / \mathrm{mmm}$ model), which might have suggested an orthorhombic distortion, was observed. This suggests that the best description of the longrange average structure of $\mathrm{Bi}_{2} \mathrm{TiO}_{4} \mathrm{~F}_{2}$ in the temperature range $100-300 \mathrm{~K}$ from NPD data is the disordered model of I4/ $\mathrm{mmm}$ symmetry (i.e. with displacive disorder of the equatorial and apical anion sites).

3.4.2. Madelung Energy Calculations for $\mathrm{Bi}_{2} \mathrm{TiO}_{4} \mathrm{~F}_{2}$. Madelung energy calculations give a measure of structural stability based on electrostatics (i.e. neglecting polarization and lone pair effects). Calculations on this $\mathrm{Bi}-\mathrm{Ti}-\mathrm{O}-\mathrm{F}$ system (see Supporting Information) indicate that the formation of $\mathrm{Bi}_{2} \mathrm{TiO}_{4} \mathrm{~F}_{2}$ (for all anion distributions) is enthalpically favorable. These calculations suggest $F$ occupancy of apical $X 2$ and fluorite $X 3$ anion sites in preference to equatorial $X 1$ sites (Madelung energies of $2.56 \times 10^{4} \mathrm{~kJ} \mathrm{~mol}^{-1}$ for equatorial $X 1=\mathrm{F} ; 2.68 \times 10^{4} \mathrm{~kJ} \mathrm{~mol}^{-1}$ for apical X2 = F, and $2.64 \times 10^{4}$ $\mathrm{kJ} \mathrm{mol}^{-1}$ for fluorite $X 3=\mathrm{F}$ were calculated). This may reflect the purely ionic nature of these calculations which do not take into account the inert pair effect of $\mathrm{Bi}^{3+}$ ions, which is likely to influence the bonding around the fluorite $X 3$ and apical $X 2$ anion sites.

3.4.3. Anion Distribution in $\mathrm{Bi}_{2} \mathrm{TiO}_{4} \mathrm{~F}_{2}$. The similar neutron scattering lengths of $\mathrm{O}$ and $\mathrm{F}$ make it difficult to determine the distribution of $\mathrm{O}^{2-}$ and $\mathrm{F}^{-}$anions over the anion sites. Bond valence sum analysis ${ }^{63,64}$ has been used to investigate anion ordering in oxyfluorides, ${ }^{19,39,54}$ and analysis by Needs et al. suggests that $\mathrm{F}^{-}$ions in $\mathrm{Bi}_{2} \mathrm{TiO}_{4} \mathrm{~F}_{2}$ are most likely to occupy the equatorial $(X 1)$ anion sites. ${ }^{39}$ Our analysis using bond lengths from our $300 \mathrm{~K}$ disordered $14 / \mathrm{mmm}$ model (see Supporting Information) is less definitive: $\mathrm{F}^{-}$occupation of the $X 1$ site gives cation valences closest to those expected but occupation of $X 2$ is preferred by the anion BVS values; $\mathrm{F}^{-}$ occupation of the $X 3$ site (within the fluorite-like $\mathrm{Bi}_{2} X_{2}$ layers) is the least favorable. Overall, the difference between $\mathrm{F}^{-}$ occupation of $X 1$ (equatorial) and $X 2$ (apical) sites is small. The stoichiometry of $\mathrm{Bi}_{2} \mathrm{TiO}_{4} \mathrm{~F}_{2}$ is consistent with $\mathrm{F}^{-}$ occupying half the anion sites in the perovskite layers, and as explained by Needs et al., ${ }^{39}$ there are three possibilities for this: the equatorial $X 1$ site could be fully occupied by $\mathrm{F}^{-}$, the apical $X 2$ site could be fully occupied by $\mathrm{F}^{-}$, or both $X 1$ and $X 2$ sites could be half-occupied by $\mathrm{F}^{-}$. It is possible that more than one site is occupied by $\mathrm{F}^{-}$ions and the anion distribution may be sensitive to synthesis temperature, cooling rate, and sample history.

\section{DISCUSSION}

4.1. Structural Analysis. Analysis of NPD data, discussed above, indicates displacements of equatorial $X 1$ and apical $X 2$ anion sites consistent with short-range tilting of $\mathrm{Ti} X_{6}$ octahedra. However, there is no evidence to suggest longrange ordering of this tilting from NPD or electron diffraction data, consistent with analysis by Needs et al. ${ }^{39}$ Tilting of the $B X_{6}$ octahedra in $\mathrm{Bi}_{2} A_{2} B_{3} \mathrm{O}_{12}$ and related Aurivillius phases is thought to occur to relieve strain in stacking the wider perovskite and more narrow fluorite-like $\left[\mathrm{Bi}_{2} \mathrm{O}_{2}\right]^{2+}$ layers (with natural a parameter $\left.a_{\mathrm{f}}=3.80 \AA\right) .{ }^{65}$ In $n=1$ Aurivillius materials with no $A$-site cations, the ideal width of the 
perovskite layers, $a_{\mathrm{p}}$, can be approximated by $a_{\mathrm{p}}=2\left(r_{\mathrm{B}}+r_{\mathrm{X}}\right)$, with $r_{\mathrm{X}}$ being the weighted mean anion radius. For $\mathrm{Bi}_{2} \mathrm{TiO}_{4} \mathrm{~F}_{2}$ $\left(r_{\mathrm{B}}=r_{\mathrm{Ti}}=0.605 \AA, r_{\mathrm{O}}=1.35 \AA \text {, and } r_{\mathrm{F}}=1.285 \AA\right)^{18}$ with $\mathrm{F}^{-}$in equatorial $X 1$ or apical X2 sites, $a_{\mathrm{p}}=3.78 \AA$ and $a_{\mathrm{p}}=3.91 \AA$, respectively. In terms of lattice mismatch, $F$ occupancy of equatorial $\mathrm{X} 1$ sites might be expected (giving perovskite blocks of a similar width to the $\left[\mathrm{Bi}_{2} \mathrm{O}_{2}\right]^{2+}$ layers) but tilting of the $\mathrm{Ti}_{6}$ octahedra, about in-plane and out-of-plane axes, can also reduce this interfacial mismatch while maintaining satisfactory $\mathrm{Ti}-X$ bond lengths. The bond valence sum analysis and our understanding of strain suggest that $\mathrm{F}$ occupancy of equatorial $\mathrm{X} 1$ sites is certainly possible in $\mathrm{Bi}_{2} \mathrm{TiO}_{4} \mathrm{~F}_{2}$ and is consistent with the conclusions of Needs et al. ${ }^{39}$ However, this contrasts with several other $n=1$ Aurivillius and Ruddlesden-Popper oxyfluorides including $\mathrm{Bi}_{2} \mathrm{NbO}_{5} \mathrm{~F},{ }^{54} \mathrm{Sr}_{2} \mathrm{ScO}_{3} \mathrm{~F},{ }^{66}$ and $\mathrm{Sr}_{2} \mathrm{MnO}_{3} \mathrm{~F},{ }^{67}$ which are reported to have $\mathrm{F}$ occupancy of apical anion sites despite similar arguments involving stacking strain between $\left[\mathrm{Bi}_{2} \mathrm{O}_{2}\right]^{2+}$ and $\mathrm{Nb}(\mathrm{O}, \mathrm{F})_{2}$ layers $\left(a_{\mathrm{p}}=3.95 \AA\right.$ and $a_{\mathrm{p}}=4.08 \AA$ for $\mathrm{F}^{-}$in equatorial $\mathrm{X} 1$ or apical $X 2$ sites, respectively) or between $\mathrm{SrO}$ and $\mathrm{Mn}(\mathrm{O}, \mathrm{F})_{2}$ layers (ideal $a_{\mathrm{SrO}}$ $\approx 3.65 \AA$; for $\mathrm{Sr}_{2} \mathrm{ScO}_{3} \mathrm{~F} a_{\mathrm{p}}=4.12 \AA$ and $a_{\mathrm{p}}=4.19 \AA$ for $\mathrm{F}^{-}$in equatorial or apical sites, respectively; for $\mathrm{Sr}_{2} \mathrm{MnO}_{3} \mathrm{~F} a_{\mathrm{p}}=3.86$ $\AA$ and $a_{\mathrm{p}}=3.99 \AA$ for $\mathrm{F}^{-}$in equatorial or apical sites, respectively). It is striking that $\mathrm{Bi}_{2} \mathrm{TiO}_{4} \mathrm{~F}_{2}$ has relatively small stacking strain compared to these examples, suggesting the possibility that anion distribution might be tuned by strain engineering, for example. ${ }^{68}$ Wider consideration of the bonding in $\mathrm{Bi}_{2} \mathrm{TiO}_{4} \mathrm{~F}_{2}$, beyond the purely ionic model, may also be relevant-particularly given the importance of $\mathrm{p} \pi \mathrm{d} \pi$ $B-\mathrm{O}$ bonding (often reflected in shorter $B-\mathrm{O}$ bonds) that can influence the stereochemistry in oxyfluorides. ${ }^{19}$ Similar factors also influence the $\mathrm{N}^{3-} / \mathrm{O}^{2-}$ order in oxynitrides. ${ }^{69}$

Bond valence sum analysis has been used to investigate possible anion ordering in other oxyfluorides, ${ }^{19}$ but the uncertainty of the anion order in $\mathrm{Bi}_{2} \mathrm{TiO}_{4} \mathrm{~F}_{2}$ from $\mathrm{BVS}$ analysis prompted us to examine the use of the more powerful "global instability index" (GII). This is a measure of lattice strain-the extent to which the valence sum rule is broken (based on bond lengths). ${ }^{70,71}$ The GII is defined as

$$
\mathrm{GII}=\sqrt{\sum_{i=1}^{N}\left\{\left(\sum_{j} s_{i j}-V_{i}\right)^{2}\right\} / N}
$$

and it gives a measure of the extent to which the observed bond valence sums at a cation site $\left(S_{i j}\right)$ differ from the theoretical cation valence $\left(V_{i}\right)$, averaged over all atoms in the formula unit. In general, it is accepted that structures with GII $<0.05$ v.u. are essentially unstrained, whereas those with GII > 0.20 v.u. are disposed toward relaxation, or distortion, in order to minimize bond strain. The key point is that the GII can give an indication of the overall structural strain on the $\mathrm{O} / \mathrm{F}$ distribution. Calculations were first carried out for the ordered $I 4 / \mathrm{mmm}$ model (i.e. equatorial and apical anions on highsymmetry $4 c$ and $4 e$ sites) but gave GII values greater than the accepted threshold value of 0.20 , regardless of anion arrangement, consistent with at least short-range tilting of $\mathrm{TiX}_{6}$ octahedra, as discussed above. The GII was then calculated for the disordered $I 4 / \mathrm{mmm}$ model of $\mathrm{Bi}_{2} \mathrm{TiO}_{4} \mathrm{~F}_{2}$ (i.e. equatorial and apical anions on lower-symmetry $16 n$ and $16 \mathrm{~m}$ sites) for various bonding anion arrangements, assuming full occupancy of all cation sites and using constraints to maintain anion stoichiometry (taking into account the site multiplicities as appropriate)

$$
\begin{aligned}
& n_{\mathrm{X} 1}+n_{\mathrm{X} 2}+n_{\mathrm{X} 3}=6 \\
& n_{\mathrm{O} 1}+n_{\mathrm{O} 2}+n_{\mathrm{O} 3}=4 \\
& n_{\mathrm{F} 1}+n_{\mathrm{F} 2}+n_{\mathrm{F} 3}=2
\end{aligned}
$$

The GII was calculated for all possible $\mathrm{O} / \mathrm{F}$ distributions at intervals of $\Delta n=0.1$. The results are shown in the form of a contour map in Figure 5. Note that, by virtue of eqs $2 a, 2 b$, and $2 c$, setting the F occupancy of the $X 1$ and $X 2$ sites defines the $F$ occupancy of the $X 3$ site and the $\mathrm{O}$ occupancy of sites $X 1, X 2$, and $X 3$.

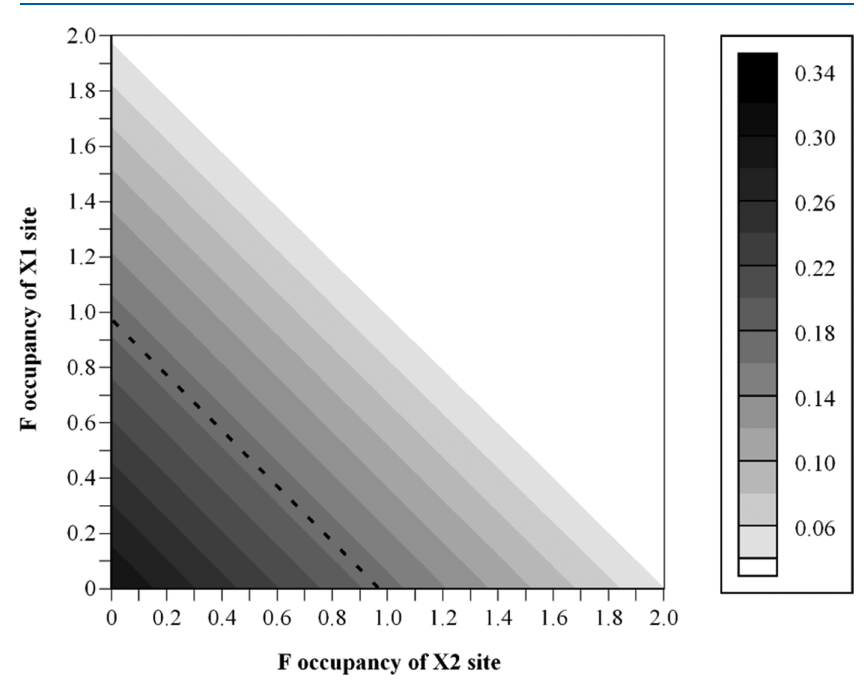

Figure 5. Contour plot showing variation of the GII with $\mathrm{F}$ occupation of anion sites in $\mathrm{Bi}_{2} \mathrm{TiO}_{4} \mathrm{~F}_{2}$, assuming that $X 1$ and $X 2$ anions are displaced to quarter occupied $16 n(x, 0.5, z)$ and $16 \mathrm{~m}(x, x$, $z$ ) general positions, respectively; increasing GII values are correlated with heavier shading. Note: contour plot assumes stoichiometric constraints defined by eqs $2 \mathrm{a}, 2 \mathrm{~b}$, and $2 \mathrm{c}$ (the white area lies outside these stoichiometric constraints). The broken line indicates the isoline defining the upper stability limit of the $\mathrm{Bi}_{2} \mathrm{TiO}_{4} \mathrm{~F}_{2}$ structure, with GII $=0.20$.

Figure 5 shows that the GII values for the disordered I4/ $\mathrm{mmm}$ models span the range corresponding to essentially unstrained $(\mathrm{GII}=0.06)$ to prohibitively strained $(\mathrm{GII}>0.20)$ structures. Further, the threshold value of GII $=0.20$ corresponds to the isoline defined by the inequality given as eq 3 (and shown by the broken line in Figure 5)

$$
n_{\mathrm{F} 1}+n_{\mathrm{F} 2} \geq n_{\mathrm{F} 3}
$$

This highlights the strain induced if $\mathrm{F}$ occupancy of the $X 3$ site exceeds that of the $X 1$ and $X 2$ sites. Importantly, the lowest GII values are calculated for structures with $F$ exclusively occupying $X 1$ and $X 2$ sites; that is, the lowest GII values correspond to the isoline defined by eq 4

$$
n_{\mathrm{F} 1}+n_{\mathrm{F} 2}=2
$$

However, GII values for the end members of this isoline differ by less than $10 \%$ (exclusive $\mathrm{F}^{-}$occupation of the equatorial $X 1$ site gives $\mathrm{GII}=0.057$; exclusive $\mathrm{F}^{-}$occupation of the apical $X 2$ site gives GII =0.062). Using the GII as an indicator of structural strain again suggests that F occupancy of equatorial $X 1$ sites is favored, but the difference in strain 
between $X 1$ and $X 2 \mathrm{~F}$ occupancy is small, and some partial occupancy would not be unexpected.

4.2. Hypothetical Anion-Ordered Models for $n=1$ Aurivillius and Ruddlesden-Popper Phases. Recent interest in designing polar materials has demonstrated that the anion sublattice can be tuned to break inversion symmetry: (oxidative) topotactic fluorination reactions have been used to tune octahedral tilts to break the inversion symmetry in Ruddlesden-Popper phases, ${ }^{17}$ and theory work has considered anion ordering to give polar heteroanionic units that might crystallize to give polar structures. ${ }^{4,5}$ This prompted us to explore hypothetical $\mathrm{O} / \mathrm{F}$ ordering patterns in $\mathrm{Bi}_{2} \mathrm{TiO}_{4} \mathrm{~F}_{2}$ more fully, and these models can equally be applied to other $n=1$ Aurivillius and Ruddlesden-Popper phases which have aristotype structures of $I 4 / \mathrm{mmm}$ symmetry.

For $\mathrm{Bi}_{2} \mathrm{TiO}_{4} \mathrm{~F}_{2}$ with $\mathrm{O}^{2-}$ anions fully occupying $X 3$ anion sites in the fluorite layers (and equally for Ruddlesden-Popper phases of $A_{2} B_{2} \mathrm{~F}_{2}$ stoichiometry), the anion sites in the perovskite layers (equatorial and apical sites) are half-occupied by $\mathrm{O}$ and $\mathrm{F}$, giving three possible anion-ordered arrangements (see Supporting Information):

(A) F fully occupies equatorial $X 1$ sites (as expected due to stacking strain in $\mathrm{Bi}_{2} \mathrm{TiO}_{4} \mathrm{~F}_{2}$ ).

(B) F fully occupies apical $X 2$ sites.

(C) $\mathrm{F}$ and $\mathrm{O}$ each half-occupy both equatorial and apical sites.

With the equatorial and apical anion positions being crystallographically distinct sites, ordered arrangements (A) and (B) do not produce any change in the symmetry (it remains centrosymmetric, $I 4 / \mathrm{mmm}$ ). The structure is built up from corner-linked nonpolar $\mathrm{TiO}_{2} \mathrm{~F}_{4 / 2}$ and $\mathrm{TiF}_{2} \mathrm{O}_{4 / 2}$ octahedra for (A) and (B), respectively (the $x / y$ notation for the equatorial sites denotes the site of multiplicity $x$ shared between $y$ cation sites).

The final arrangement, $(\mathrm{C})$, is interesting because it results in a polar $\mathrm{Ti}\left(\mathrm{O}_{1 / 2} \mathrm{~F}_{1 / 2}\right)_{\text {ap }}\left(\mathrm{O}_{2 / 2} \mathrm{~F}_{2 / 2}\right)_{\text {eq }}$ corner-linked octahedra, that is, either mer- or fac- $\left[\mathrm{TiO}_{3} \mathrm{~F}_{3}\right]$ units (Figure $6 \mathrm{c}$ ). The bond valence sum and GII analysis described above for $\mathrm{Bi}_{2} \mathrm{TiO}_{4} \mathrm{~F}_{2}$ suggest that while arrangement $(\mathrm{A})$ is most favored, the difference between arrangements $(\mathrm{A})$ and $(\mathrm{B})$ is small and so (C) might occur over short length scales or could be accessed by strain engineering as demonstrated in strontium manganese oxyfluoride films. ${ }^{68}$

The mer- or fac- $\left[\mathrm{TiO}_{3} \mathrm{~F}_{3}\right]$ heteroanionic units are both polar, and it is interesting to consider the symmetry of different packing arrangements and whether possible anion ordering could break inversion symmetry to give polar structures. As for our exploration of displacive distortions (Section 3.4.1), ISODISTORT $^{57,58}$ was again used to explore occupancy modes that might give rise to anion-ordered arrangements, and these are illustrated in Figure 6:

- $\Gamma_{3}{ }^{-}, \mathrm{M}_{3}{ }^{-}$, and $\mathrm{X}_{2}{ }^{-}$modes can give ordered halfoccupancy of apical sites by $\mathrm{O}$ and $\mathrm{F}$.

- $\Gamma_{2}{ }^{+}$and $\mathrm{M}_{2}{ }^{+}$modes can give ordered half-occupancy of equatorial sites in a trans fashion.

- $\mathrm{X}_{3}{ }^{-}$and $\mathrm{X}_{4}^{-}$modes can give ordered half-occupancy of equatorial sites in a cis fashion.

Combinations of apical and equatorial anion modes can be combined to give mer- and $f a c-\mathrm{TiO}_{3} \mathrm{~F}_{3}$ octahedra with packing of various symmetries (see Table 2 and Supporting Information). Many of these occupancy modes have been explored more generally by Harada et al., ${ }^{5}$ but we focus here (a) Equatorial anion-ordering modes
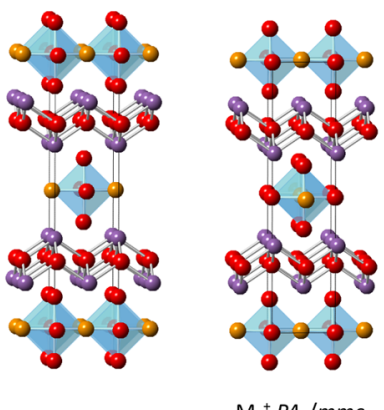

$\mathrm{M}_{2}{ }^{+} \mathrm{PL}_{2} / m m c$
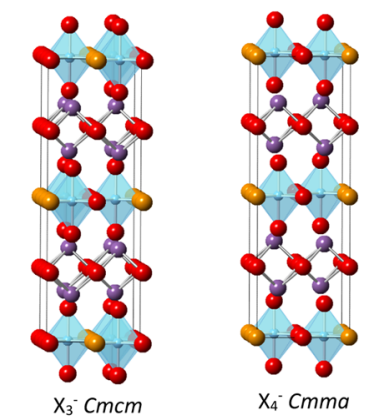

(b) Apical ordering modes

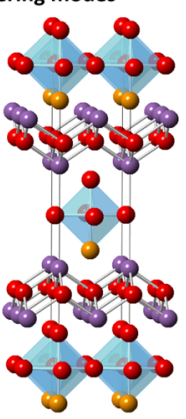

$\Gamma_{3} \cdot 14 \mathrm{~mm}$

(c)

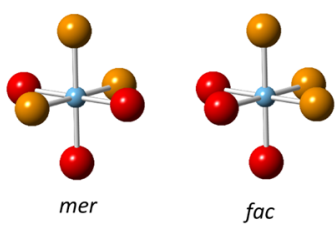

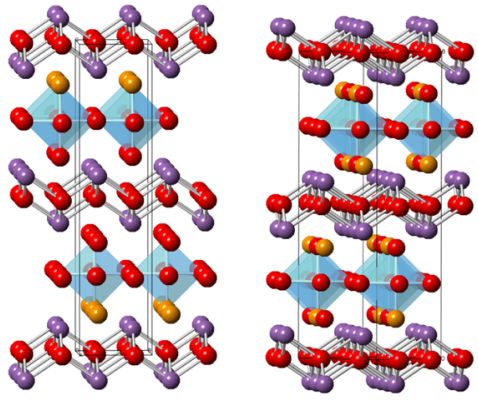

$\mathrm{M}_{3}{ }^{-} P 4 / n m m$ (d)

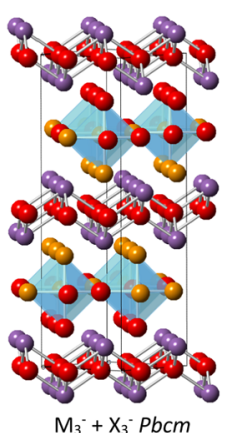

Figure 6. Illustration of (a) equatorial occupancy modes and (b) apical occupancy modes that can be combined to give anion-ordered structures containing mer- and $f a c-\mathrm{TiO}_{3} \mathrm{~F}_{3}$ octahedra in $\mathrm{Bi}_{2} \mathrm{TiO}_{4} \mathrm{~F}_{2} ; \mathrm{Bi}$, $\mathrm{Ti}, \mathrm{O}$, and $\mathrm{F}$ are shown in purple, blue, red, and orange, respectively. Analysis was carried out using ISODISTORT using the ordered I4/ $\mathrm{mmm}$ model as the parent structure; (c) isolated mer- and $f a c-\mathrm{TiO}_{3} \mathrm{~F}_{3}$ units and (d) $\mathrm{fac} \mathrm{Pbcm}$ model (derived from $\mathrm{M}_{3}^{-}$apical ordering and $\mathrm{X}_{3}^{-}$equatorial ordering modes).

on those possible in $n=1$ Aurivillius and Ruddlesden-Popper phases.

Both mer- and $\mathrm{fac}-\mathrm{TiO}_{3} \mathrm{~F}_{3}$ units are polar (the polar axis is along the $C_{4}$ axis in $m e r-\mathrm{TiO}_{3} \mathrm{~F}_{3}$ and along the $C_{3}$ axis in $\mathrm{fac}$ $\mathrm{TiO}_{3} \mathrm{~F}_{3}$ ), and $\mathrm{d}^{0} \mathrm{Ti}^{4+}$ ions might be expected to displace away from the center of the unit toward the $\mathrm{O}^{2-}$ anions. ${ }^{19}$ As highlighted by Withers et al., the challenge in using anion ordering to design polar materials lies in controlling the relative orientations of the polar units ${ }^{19}$ and, in $\mathrm{Bi}_{2} \mathrm{TiO}_{4} \mathrm{~F}_{2}$, only the polar $\Gamma_{3}^{-}$occupancy mode (which acts on the apical anion sites) gives polar anion-ordered structures in these cases with out-of-plane polarization along the long axis.

Although it is not possible to differentiate between these different $\mathrm{O} / \mathrm{F}$ ordering patterns using NPD (due to the similar $\mathrm{O}$ and $\mathrm{F}$ neutron scattering lengths), the symmetry lowering caused by the anion order allows other structural degrees of freedom, such as cation displacements, which NPD may be 
Table 2. Summary of Anion-Ordered $\mathrm{Bi}_{2} \mathrm{TiO}_{4} \mathrm{~F}_{2}$ Structures Containing mer- and fac- $\mathrm{TiO}_{3} \mathrm{~F}_{3}$ Units in $\mathrm{Bi}_{2} \mathrm{TiO}_{4} \mathrm{~F}_{2}{ }^{a}$

\begin{tabular}{|c|c|c|c|c|}
\hline $\begin{array}{l}\text { apical } \\
\text { ordering } \\
\text { mode }\end{array}$ & $\begin{array}{c}\text { equatorial } \\
\text { ordering mode }\end{array}$ & $\begin{array}{l}\text { unit cell } \\
\text { symmetry }\end{array}$ & $\begin{array}{c}\mathrm{TiO}_{3} \mathrm{~F}_{3} \\
\text { isomerism }\end{array}$ & $\begin{array}{l}\text { optimized GII at } \\
300 \mathrm{~K} \text { (v. u.) }\end{array}$ \\
\hline \multirow[t]{4}{*}{$\Gamma_{3}^{-}$} & $\Gamma_{2}^{+}$ & $\operatorname{Im} m 2$ & mer & $0.24(4)$ \\
\hline & $\mathrm{M}_{2}^{+}$ & $\mathrm{P}_{2}{ }_{2} \mathrm{mc}$ & mer & $0.29(3)$ \\
\hline & $\mathrm{X}_{3}^{-}$ & Ama 2 & $f a c$ & $0.11(2)$ \\
\hline & $\mathrm{X}_{4}^{-}$ & $A b m 2$ & $f a c$ & $0.18(3)$ \\
\hline \multirow[t]{4}{*}{$\mathrm{M}_{3}^{-}$} & $\Gamma_{2}^{+}$ & Pmmn & mer & $0.16(1)$ \\
\hline & $\mathrm{M}_{2}^{+}$ & $P \overline{4} m 2$ & mer & $0.15(1)$ \\
\hline & $\mathrm{X}_{3}^{-}$ & $\mathrm{Pbcm}$ & $f a c$ & $0.09(1)$ \\
\hline & $\mathrm{X}_{4}^{-}$ & $P c c m$ & $f a c$ & $0.15(1)$ \\
\hline \multirow[t]{6}{*}{$\mathrm{X}_{2}^{-}$} & $\Gamma_{2}^{+}$ & $C 2 / c$ & mer & $0.15(2)$ \\
\hline & $\mathrm{M}_{2}^{+}$ & Pnna & mer & $0.17(2)$ \\
\hline & $\mathrm{X}_{3}^{-}$ & Pnma & $f a c$ & $0.27(4)$ \\
\hline & & $P 2_{1} / m$ & & \\
\hline & $\mathrm{X}_{4}^{-}$ & $\mathrm{Pbcm}$ & $f a c$ & $0.24(3)$ \\
\hline & & $\mathrm{C} 2 / \mathrm{m}$ & & \\
\hline
\end{tabular}

${ }^{a}$ Analysis was carried out using ISODISTORT using the ordered I4/ $\mathrm{mmm}$ model as the parent structure. GII values were calculated from 300 K NPD Rietveld refinement with bond valence penalties to allow refinement of unit cell parameters and atomic coordinates (as allowed by symmetry).

sensitive to. However, if these are subtle or short-range, they may not always be detected by standard methods (such distortions may give only diffuse scatter or weak superstructure reflections) making it hard to distinguish between numerous similar models.

Harada et al. have shown elegantly that the GII can be used to screen potential structures to rule out those with high lattice strain. Their approach involved refining unit cell parameters to minimize the GII (although this could be developed to include lattice degrees of freedom), although it required some constraints on changes in unit cell parameters and the degree of orthorhombic distortion. ${ }^{5}$ Given the recent interest in oxyfluorides and the challenges in investigating anion ordering, $^{21}$ we have built on the GII approach and used the GII as a means of introducing lattice strain information into our Rietveld refinements. This method might be applied more widely to investigate the anion order in heteroanionic materials with similar scattering lengths for the two anions. Structural refinements of the anion-ordered models in Table 2 were carried out using the Rietveld method with additional local subroutines to introduce penalty functions to minimize the difference between the experimental valence and the expected valence for each site (based on bond lengths from the refined structure; see section from the TopasAcademic input file in Supporting Information). This allows the structural model to refine in order to improve the fit to the diffraction data and to minimize bond valence sums, which gives an optimized value for the GII. This is similar to the approach used by Thompson et al., ${ }^{72}$ but the flexibility of the input files for TopasAcademic $^{52}$ allows the least squares refinements to be carried out within a single program. This approach uses the experimental diffraction data (in this case, $300 \mathrm{~K} \mathrm{NPD}$ data) to constrain the structural model rather than additional more arbitrary constraints. Nevertheless, by using penalties for both cation and anion sites, most structures refined to give $\mathrm{Ti}-\mathrm{O}$ bonds shorter than $\mathrm{Ti}-\mathrm{F}$ bonds. This is consistent with structures reported for $\mathrm{NdNiO}_{2} \mathrm{~F},{ }^{73} \alpha-A_{3} \mathrm{MoO}_{3} \mathrm{~F}_{3}(A=\mathrm{Rb}$ and $\mathrm{K}),{ }^{1,4}$ and other oxyfluorides. ${ }^{19}$ For both $\Gamma_{3}{ }^{-}$and $\mathrm{M}_{3}{ }^{-}$apical ordering, the GII results in Table 2 and Figure 7 suggest that, in general, the $f a c$ structures are less strained than the equivalent mer

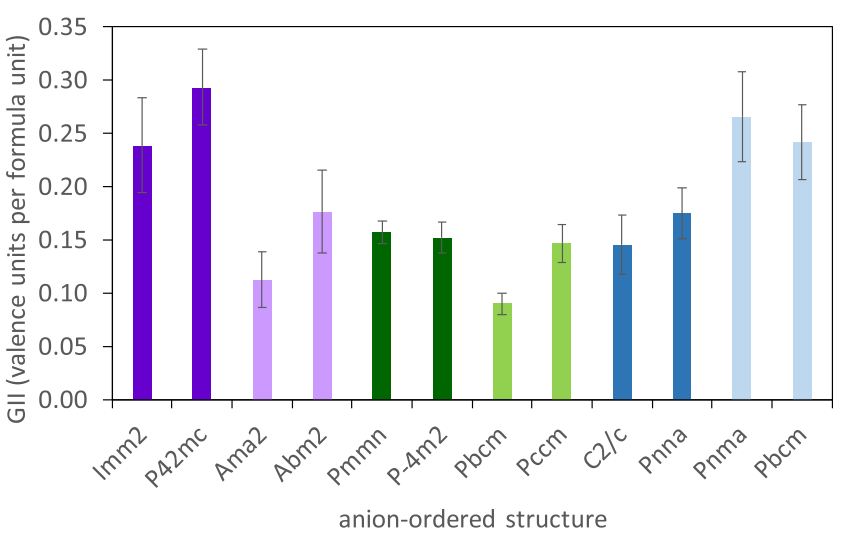

Figure 7. Showing GII values for combined Rietveld and BVS refinements for the anion-ordered models in Table 2; models from $\Gamma_{3}^{-}$(polar), $\mathrm{M}_{3}^{-}$, and $\mathrm{X}_{2}^{-}$apical ordering modes are shown in purple, green, and blue, respectively, with mer and fac isomers shown in dark and light shades.

structures, which is again consistent with the importance of $\mathrm{p} \pi$ $\mathrm{d} \pi$ bonding between oxygen and $\mathrm{d}^{0}$ cations, favoring cis and fac isomers with shorter $\mathrm{Ti}-\mathrm{O}$ bonds. ${ }^{19}$

It is worth noting that cis- and trans-isomers are similarly favored for oxynitrides (for which $\mathrm{N}^{3-}$ is the more covalent ligand). ${ }^{69}$ However, this preference rarely gives long-range $\mathrm{N}^{3-} / \mathrm{O}^{2-}$ order, and instead, a correlated order (comprising cisanion chains) emerges. ${ }^{74}$ This lack of long-range site order is thought to disrupt long-range correlations between any polar displacement in the oxynitrides, ${ }^{75,76}$ limiting the length scale of any polar region and can give polar nanoregions. ${ }^{7}$

4.3. Polar Structures from Nonpolar Anion Order and Nonpolar Tilts. The GII values for many of these structures, derived from the ordered $14 / \mathrm{mmm}$ model, are higher than those calculated above for the disordered $14 / \mathrm{mmm}$ model. It is likely that lattice strain would be further relieved in these anion-ordered models by rotation of $\mathrm{TiO}_{3} \mathrm{~F}_{3}$ octahedra, even if only over short length scales, and it is interesting to consider the symmetry implications of this (see Supporting Information for full details). For several nonpolar anion-ordered structures in Table 2, allowing a nonpolar octahedral rotation mode (e.g. either about an in-plane axis or about the out-of-plane axis) can break the inversion symmetry and give a polar structure, either with out-of-plane polarization (described by the $\Gamma_{3}{ }^{-}$ irrep), which is somewhat unusual in Aurivillius materials, or with the more commonly observed in-plane polarization (described by the $\Gamma_{5}^{-}$irrep). This combination of anion order coupled with nonpolar distortions to break the inversion symmetry has been reported for $\alpha-A_{3} \mathrm{MoO}_{3} \mathrm{~F}_{3}(A=\mathrm{Rb}, \mathrm{K})^{14}$ and provides a further avenue for research into hybridimproper origins of polar behavior. ${ }^{78}$ The coupling between the rotational modes, polar distortions, and anion ordering is worthy of further study, and we now consider combinations of tilts and anion ordering. The $f a c$ model of the $P b c m$ symmetry $\left(\mathrm{M}_{3}^{-}\right.$and $\mathrm{X}_{3}^{-}$anion ordering modes) has a low GII. Introducing rotations of $\mathrm{TiO}_{3} \mathrm{~F}_{3}$ octahedra about the out-ofplane axis $\left(00 \theta 00 \theta, \mathrm{X}_{2}^{+}\right.$irrep; see Section 3.4.1 above and Supporting Information) lowers the symmetry to $P c a 2_{1}$, allowing in-plane polar distortions $\left(\Gamma_{5}\right.$-irrep) and rotation of $\mathrm{TiO}_{3} \mathrm{~F}_{3}$ octahedra about an in-plane axis (ФФ0 ФФ0, $\mathrm{X}_{3}^{+}$ 
irrep; see Section 3.4.1 above and Supporting Information). This combination of tilts has been reported for other $n=1$ Aurivillius phases including $\mathrm{Bi}_{2} \mathrm{MoO}_{6},{ }^{79,80} \mathrm{Bi}_{2} \mathrm{WO}_{6},{ }^{24,28}$ and $\mathrm{Bi}_{2} \mathrm{NbO}_{5} \mathrm{~F}^{54}$ and the in-plane polar displacements along $[110]_{\mathrm{t}}$ are frequently observed in Aurivillius materials. Given that this symmetry is compatible with a $f a c-\mathrm{TiO}_{3} \mathrm{~F}_{3}$ structure predicted to have fairly low strain, it would be interesting to explore how such a phase could be realized. Rietveld refinement for $\mathrm{Bi}_{2} \mathrm{TiO}_{4} \mathrm{~F}_{2}$ using this $P c a 2_{1}$ model with bond valence penalties gives a GII of $0.05(7)$, comparable to the disordered $I 4 / \mathrm{mmm}$ model discussed above; although as noted above, the model does not give intensity for the superstructure reflections (see Supporting Information).

The local (rather than long-range) nature of octahedral tilting may result from the lack of long-range order on the anion sublattice, and the extent of any anion order may be very sensitive to precise composition, reaction temperature, and pressure and any annealing and sample cooling rate. This may explain the observed ferroelectric $T_{\mathrm{C}}=284 \mathrm{~K}$ reported by Ismailzade and Ravez, ${ }^{47}$ which was not seen in other studies on polycrystalline samples of $\mathrm{Bi}_{2} \mathrm{TiO}_{4} \mathrm{~F}_{2}$ (here and Needs et al. ${ }^{39}$ ). Epitaxial methods for thin film growth may provide a means of controlling the anion arrangement, and the choice of substrates may also influence the lattice strain and tilting; these considerations likely explain the ferroelectric transition at $\sim 240 \mathrm{~K}$ reported in thin films of $\mathrm{Bi}_{2} \mathrm{TiO}_{4} \mathrm{~F}_{2}{ }^{48}$ and may be relevant to its photocatalytic behavior. ${ }^{45}$

\section{CONCLUSIONS}

This work highlights the preferences for $\mathrm{F}^{-}$occupancy in the perovskite anion sites in the photocatalyst $\mathrm{Bi}_{2} \mathrm{TiO}_{4} \mathrm{~F}_{2}$, and our exploration of strain and bonding helps to explain this preference and how it might be tuned. This is particularly relevant to the structure and behavior of this class of materials in thin film and nanostructured forms where strain could well result in different anion distributions to those observed in bulk ceramic samples. Our symmetry analysis demonstrates the possibility of anion order alone breaking inversion symmetry in a small number of cases in $\mathrm{Bi}_{2} \mathrm{TiO}_{4} \mathrm{~F}_{2}$ as well as several possibilities for the anion order combined with nonpolar octahedral rotations to break inversion symmetry. This is similar to the findings by Fry and Woodward ${ }^{14}$ and provides a new avenue to explore in designing hybrid improper polar materials. ${ }^{78}$ The displacive disorder of the anion sites observed in bulk ceramic samples (here and Needs et al. ${ }^{39}$ ) is likely to disrupt tendencies for $\mathrm{O}^{2-} / \mathrm{F}^{-}$ordering over the anion sites, but the possibility of local regions that are non-centrosymmetric (similar to recent reports in oxynitrides ${ }^{77}$ ) has potential for the design of new materials with relaxor-like properties. ${ }^{81}$ Our use of the Rietveld method combined with bond valence penalties $^{63,64}$ can give additional chemical information for the structural analysis of systems with atoms of similar scattering lengths.

\section{ASSOCIATED CONTENT}

\section{SI Supporting Information}

The Supporting Information is available free of charge at https://pubs.acs.org/doi/10.1021/acs.inorgchem.1c01933.

Preliminary XRPD data, electron diffraction, details from Rietveld refinements using further models, symmetry map showing common structural distortions for $A_{2} B X_{4}$ and $\mathrm{Bi}_{2} B X_{6}$ materials, mode inclusion, bond valence sum analysis, results of Madelung energy calculations, symmetry map illustrating space group, excerpt from input file for TopasAcademic software for Rietveld refinement using bond valence penalties, symmetries of anion-ordered structure with tilts of $\mathrm{TiO}_{3} \mathrm{~F}_{3}$ octahedra, symmetries of anion-ordered $n=1$ Aurivillius phases assuming an ideal parent structure, and crystallographic data from refinements using powder diffraction data (PDF)

\section{AUTHOR INFORMATION}

\section{Corresponding Authors}

Neil C. Hyatt - Department of Materials Science and Engineering, The University of Sheffield, Sheffield S1 3JD, U.K.; (1) orcid.org/0000-0002-2491-3897;

Email: n.c.hyatt@sheffield.ac.uk

Emma E. McCabe - School of Physical Sciences, University of Kent, Canterbury, Kent CT2 7NH, U.K.; Department of Physics, Durham University, Durham DH1 3LE, U.K.; (1) orcid.org/0000-0001-5868-4570; Email: emma.mccabe@durham.ac.uk

\section{Authors}

Andrew T. Giddings - Department of Materials Science and Engineering, The University of Sheffield, Sheffield S1 3JD, U.K.

Euan A. S. Scott - School of Physical Sciences, University of Kent, Canterbury, Kent CT2 7NH, U.K.

Martin C. Stennett - Department of Materials Science and Engineering, The University of Sheffield, Sheffield S1 3JD, U.K.; $\odot$ orcid.org/0000-0002-8363-9103

David C. Apperley - Department of Chemistry, Durham University, Durham DH1 3LE, U.K.

Colin Greaves - School of Chemistry, The University of Birmingham, Birmingham B15 2TT, U.K.; 이이.org/ 0000-0002-9568-3697

Complete contact information is available at: https://pubs.acs.org/10.1021/acs.inorgchem.1c01933

\section{Notes}

The authors declare no competing financial interest.

\section{ACKNOWLEDGMENTS}

This paper is in memoriam of Dr. Andrew Trevor Giddings, BEng, PhD, 1982-2018. We are grateful to have had the opportunity to work and live alongside him, benefitting from his boundless enthusiasm for life. We thank funding agencies including the Royal Society (international exchange scheme IES $\backslash$ R3 $\backslash 170112$ ), The Leverhulme Trust (RPG-2017-362), and EU Cost Action "Towards oxide-based electronics". We are grateful to the ISIS Neutron and Muon Source (STFC) for the provision of beamtime and to Dr. Kevin Knight for assistance. We enjoyed the fruitful discussions with Dr. Hania Djani and Dr. Eric Bousquet (Université de Liège). This research was supported in part by the award of an EPSRC studentship to A.T.G., EPSRC award EP/S01019X/1, and the HADES/MIDAS facility established with financial support from EPSRC and BEIS, under grant EP/T011424/1. ${ }^{75}$ 


\section{REFERENCES}

(1) Charles, N.; Saballos, R. J.; Rondinelli, J. M. Structural Diversity from Anion Order in Heteroanionic Materials. Chem. Mater. 2018, 30, $3528-3537$.

(2) Kageyama, H.; Hayashi, K.; Maeda, K.; Attfield, J. P.; Hiroi, Z.; Rondinelli, J. M.; Poeppelmeier, K. R. Expanding frontiers in materials chemistry and physics with multiple anions. Nat. Commun. 2018, 9, 772.

(3) Kobayashi, Y.; Tsujimoto, Y.; Kageyama, H. Property Engineering in Perovskites via Modification of Anion Chemistry. In Annual Review of Materials Research; Clarke, D. R., Ed., 2018; Vol. 48, pp 303-326.

(4) Harada, J. K.; Charles, N.; Poeppelmeier, K. R.; Rondinelli, J. M. Heteroanionic Materials by Design: Progress Toward Targeted Properties. Adv. Mater. 2019, 31, 1805295.

(5) Harada, J. K.; Poeppelmeier, K. R.; Rondinelli, J. M. Predicting the structure stability of layered heteroanionic materials exhibiting anion order. Inorg. Chem. 2019, 58, 13229-13240.

(6) Chien, P.-H.; Harada, J. K.; Liu, H.; Patel, S.; Huang, C.; Rondinelli, J. M.; Poeppelmeier, K. R.; Hu, Y.-Y. Microscopic Insights into the Reconstructive Phase Transition of KNaNbOF5 with 19F NMR Spectroscopy. Chem. Mater. 2020, 32, 5715-5722.

(7) Ishikawa, A.; Takata, T.; Kondo, J. N.; Hara, M.; Kobayashi, H.; Domen, K. Oxysulfide $\mathrm{Sm}_{2} \mathrm{Ti}_{2} \mathrm{~S}_{2} \mathrm{O}_{5}$ as a stable photocatalyst for water oxidation and reduction under visible light irradiation (lambda $\leq 650$ nm). J. Am. Chem. Soc. 2002, 124, 13547-13553.

(8) Kabbour, H.; Sayede, A.; Saitzek, S.; Lefevre, G.; Cario, L.; Trentesaux, M.; Roussel, P. Structure of the water-splitting photocatalyst oxysulfide alpha- $\mathrm{LaOInS}_{2}$ and ab initio prediction of new polymorphs. Chem. Commun. 2020, 56, 1645-1648.

(9) Stock, C.; McCabe, E. E. The magnetic and electronic properties of oxyselenides-influence of transition metal ions and lanthanides. $J$. Phys.: Condens. Matter 2016, 28. DOI: 10.1088/0953-8984/28/45/ 453001

(10) Wissel, K.; Heldt, J.; Groszewicz, P. B.; Dasgupta, S.; Breitzke, H.; Donzelli, M.; Waidha, A. I.; Fortes, A. D.; Rohrer, J.; Slater, P. R.; Buntkowsky, G.; Clemens, O. Topochemical Fluorination of $\mathrm{La}_{2} \mathrm{NiO}_{4+\mathrm{d}}$ : Unprecedented Ordering of Oxide and Fluoride Ions in La2NiO3F2. Inorg. Chem. 2018, 57, 6549-6560.

(11) Al-mamouri, M.; Edwards, P. P.; Greaves, C.; Slaski, M. Synthesis and superconducting properties of the strontium copper oxyfluoride $\mathrm{Sr}_{2} \mathrm{CuO}_{2} \mathrm{~F}_{2+\mathrm{d}}$. Nature 1994, 369, 382-384.

(12) Li, Y.-Y.; Wang, W.-J.; Wang, H.; Lin, H.; Wu, L.-M. MixedAnion Inorganic Compounds: A Favorable Candidate for Infrared Nonlinear Optical Materials. Cryst. Growth Des. 2019, 19, 41724192.

(13) Wang, R.; Liang, F.; Wang, F.; Guo, Y.; Zhang, X.; Xiao, Y.; Bu, K.; Lin, Z.; Yao, J.; Zhai, T.; Huang, F. $\mathrm{Sr}_{6} \mathrm{Cd}_{2} \mathrm{Sb}_{6} \mathrm{O}_{7} \mathrm{~S}_{10}$ : Strong SHG Response Activated by Highly Polarizable $\mathrm{Sb} / \mathrm{O} / \mathrm{S}$ Groups. Angew. Chem., Int. Ed. 2019, 58, 8078-8081.

(14) Fry, A. M.; Woodward, P. M. Structures of alpha- $\mathrm{K}_{3} \mathrm{MoO}_{3} \mathrm{~F}_{3}$ and alpha- $\mathrm{Rb}_{3} \mathrm{MoO}_{3} \mathrm{~F}_{3}$ : Ferroelectricity from Anion Ordering and Noncooperative Octahedral Tilting. Cryst. Growth Des. 2013, 13, 5404-5410.

(15) Greaves, C.; Francesconi, M. G. Fluorine insertion in inorganic materials. Curr. Opin. Solid State Mater. Sci. 1998, 3, 132-136.

(16) McCabe, E. E.; Greaves, C. Fluorine insertion reactions into pre-formed metal oxides. J. Fluorine Chem. 2007, 128, 448-458.

(17) Zhang, R.; Senn, M. S.; Hayward, M. A. Directed Lifting of Inversion Symmetry in Ruddlesden-Popper Oxide-Fluorides: Toward Ferroelectric and Multiferroic Behavior. Chem. Mater. 2016, 28, 8399-8406.

(18) Shannon, R. D. Revised effective ionic radii and systematic studies of interatomic distances in halides and chalcogenides. Acta Crystallogr. 1976, 32, 751-767.

(19) Withers, R. L.; Brink, F. J.; Liu, Y.; Norén, L. Cluster chemistry in the solid state: Structured diffuse scattering, oxide/fluoride ordering and polar behaviour in transition metal oxyfluorides. Polyhedron 2007, 26, 290-299.
(20) Sears, V. F. Neutron scattering lengths and cross sections. Neutron News 1992, 3, 29-37.

(21) Laptash, N. M.; Udovenko, A. A. On the identification of oxygen and fluorine atoms in disordered inorganic oxyfluoride compounds. J. Struct. Chem. 2016, 57, 390-398.

(22) de Araujo, C. A.-P.; Cuchiaro, J. D.; McMillan, L. D.; Scott, M. C.; Scott, J. F. Fatigue-free ferroelectric capacitors with platinum electrodes. Nature 1995, 374, 627-629.

(23) Fang, P. H.; Robbins, C. R.; Aurivillius, B. Ferroelectricity in compound $\mathrm{Bi}_{4} \mathrm{Ti}_{3} \mathrm{O}_{12}$. Phys. Rev. 1962, 126, 892.

(24) Okudera, H.; Sakai, Y.; Yamagata, K.; Takeda, H. Structure of russellite $\left(\mathrm{Bi}_{2} \mathrm{WO}_{6}\right)$ : origin of ferro-electricity and the effect of the stereoactive lone electron pair on the structure. Acta Crystallogr., Sect. B: Struct. Sci., Cryst. Eng. Mater. 2018, 74, 295-303.

(25) Djani, H.; Hermet, P.; Ghosez, P. First-Principles Characterization of the $\mathrm{P}_{1}$ ab Ferroelectric Phase of Aurivillius $\mathrm{Bi}_{2} \mathrm{WO}_{6}$. J. Phys. Chem. C 2014, 118, 13514-13524.

(26) Djani, H.; Bousquet, E.; Kellou, A.; Ghosez, P. First-principles study of the ferroelectric Aurivillius phase $\mathrm{Bi}_{2} \mathrm{WO}_{6}$. Phys. Rev. B: Condens. Matter Mater. Phys. 2012, 86, 054107.

(27) Thompson, J. G.; Schmid, S.; Withers, R. L.; Rae, A. D.; Gerald, J. D. F. Comparison of the crystal structures of $\gamma-\mathrm{B}_{\mathrm{i} 2} \mathrm{MoO}_{6}$ and $\mathrm{Bi}_{2} \mathrm{WO}_{6}$. J. Solid State Chem. 1992, 101, 309-321.

(28) Knight, K. S. The crystal structure of Russelite - a redetermination using neutron powder diffraction of synthetic $\mathrm{Bi}_{2} \mathrm{WO}_{6}$. Mineral. Mag. 1992, 56, 399-409.

(29) Rae, A. D.; Thompson, J. G.; Withers, R. L. Structure refinement of commensurately modulated bismuth tungstate, $\mathrm{Bi}_{2} \mathrm{WO}_{6}$. Acta Crystallogr., Sect. B: Struct. Sci. 1991, 47, 870-881.

(30) McDowell, N. A.; Knight, K. S.; Lightfoot, P. Unusual hightemperature structural behaviour in ferroelectric $\mathrm{Bi}_{2} \mathrm{WO}_{6}$. Chem.Eur. J. 2006, 12, 1493-1499.

(31) Knight, K. S. The crystal structure of ferroelectric Bi2WO6 at 961 K. Ferroelectrics 1993, 150, 319-330.

(32) Sankar, G.; Roberts, M. A.; Thomas, J. M.; Kulkarni, G. U.; Rangavittal, N.; Rao, C. N. R. Probing the structural-changes in the phase-transitions of a $\mathrm{Bi}_{2} \mathrm{MoO}_{6}$ catalyst - the nature of the intermediate-temperature phase. J. Solid State Chem. 1995, 119, 210-215.

(33) Liu, X.; Gu, S.; Zhao, Y.; Zhou, G.; Li, W. $\mathrm{BiVO}_{4}, \mathrm{Bi}_{2} \mathrm{WO}_{6}$ and $\mathrm{Bi}_{2} \mathrm{MoO}_{6}$ photocatalysis: A brief review. J. Mater. Sci. Technol. 2020, $56,45-68$.

(34) Zhang, N.; Ciriminna, R.; Pagliaro, M.; Xu, Y.-J. Nanochemistry-derived $\mathrm{Bi}_{2} \mathrm{WO}_{6}$ nanostructures: towards production of sustainable chemicals and fuels induced by visible light. Chem. Soc. Rev. 2014, 43, 5276-5287.

(35) Yu, H.; Jiang, L.; Wang, H.; Huang, B.; Yuan, X.; Huang, J.; Zhang, J.; Zeng, G.-. Modulation of $\mathrm{Bi}_{2} \mathrm{MoO}_{6}$-Based Materials for Photocatalytic Water Splitting and Environmental Application: a Critical Review. Small 2019, 15, 1901008.

(36) Guo, J.; Shi, L.; Zhao, J.; Wang, Y.; Tang, K.; Zhang, W.; Xie, C.; Yuan, X. Enhanced visible-light photocatalytic activity of $\mathrm{Bi}_{2} \mathrm{MoO}_{6}$ nanoplates with heterogeneous $\mathrm{Bi} 2 \mathrm{MoO} 6-\mathrm{x} @ \mathrm{Bi}_{2} \mathrm{MoO}_{6}$ core-shell structure. Acta Crystallogr., Sect. B: Struct. Sci., Cryst. Eng. Mater. 2018, 224, 692-704.

(37) Aurivillius, $\mathrm{B}$. The structure of $\mathrm{Bi}_{2} \mathrm{NbO}_{5} \mathrm{~F}$ and isomorphous compounds. Ark. Kemi 1952, 4, 39-47.

(38) Akopjan, A. V.; Serov, T. V.; Dolgikh, V. A.; Ardaschnikova, E. I.; Lightfoot, P. A new anion conductive bismuth-vanadium oxyfluoride. J. Mater. Chem. 2002, 12, 1490-1494.

(39) Needs, R. L.; Dann, S. E.; Weller, M. T.; Cherryman, J. C.; Harris, R. K. The structure and oxide/fluoride ordering of the ferroelectrics $\mathrm{Bi}_{2} \mathrm{TiO}_{4} \mathrm{~F}_{2}$ and $\mathrm{Bi}_{2} \mathrm{NbO}_{5} \mathrm{~F}$. J. Mater. Chem. 2005, 15, 2399-2407.

(40) Mitoudi-Vagourdi, E.; Müllner, S.; Lemmens, P.; Kremer, R. K.; Johnsson, M. Synthesis and Characterization of the Aurivillius Phase $\mathrm{CoBi}_{2} \mathrm{O}_{2} \mathrm{~F}_{4}$. Inorg. Chem. 2018, 57, 9115-9121.

(41) Yu, X.; Mitoudi-Vagourdi, E.; Johnsson, M. The Aurivillius Compound $\mathrm{CoBi}_{2} \mathrm{O}_{2} \mathrm{~F}_{4}$ - an Efficient Catalyst for Electrolytic Water 
Oxidation after Liquid Exfoliation. Chemcatchem 2019, 11, 61056110.

(42) Lei, S.; Cheng, D.; Gao, X.; Fei, L.; Lu, W.; Zhou, J.; Xiao, Y.; Cheng, B.; Wang, Y.; Huang, H. A new low-temperature solution route to Aurivillius-type layered oxyfluoride perovskites $\mathrm{Bi}_{2} M \mathrm{O}_{5} \mathrm{~F}(M$ $=\mathrm{Nb}, \mathrm{Ta}$ ) as photocatalysts. Acta Crystallogr., Sect. B: Struct. Sci., Cryst. Eng. Mater. 2017, 205, 112-120.

(43) Lei, S.; Wang, C.; Cheng, D.; Gao, X.; Chen, L.; Yan, Y.; Zhou, J.; Xiao, Y.; Cheng, B. Hierarchical $\mathrm{BiF}_{3}-\mathrm{Bi}_{2} \mathrm{NbO}_{5} \mathrm{~F}$ Core-Shell Structure and Its Application in the Photosensitized Degradation of Rhodamine B under Visible Light Irradiation. J. Phys. Chem. C 2015, $119,502-511$.

(44) Jiang, B.; Zhang, P.; Zhang, Y.; Wu, L.; Li, H.; Zhang, D.; Li, G. Self-assembled $3 \mathrm{D}$ architectures of $\mathrm{Bi}_{2} \mathrm{TiO}_{4} \mathrm{~F}_{2}$ as a new durable visiblelight photocatalyst. Nanoscale 2012, 4, 455-460.

(45) Chen, J.; Liu, H.; Zhu, L.; Fu, Z.; Lu, Y. One-pot synthesis of $\mathrm{Bi}_{2} \mathrm{TiO}_{4} \mathrm{~F}_{2} / \mathrm{BiOBr}$ ferroelectric heterostructure for photocatalytic oxygen evolution. J. Alloys Compd. 2021, 873, 159847.

(46) Abrahams, S. C.; Ravez, J. Dielectric and related properties of fluorine-octahedra ferroelectrics. Ferroelectrics 1992, 135, 21-37.

(47) Ismailzade, I. H.; Ravez, J. $\mathrm{Bi}_{2} \mathrm{TiO}_{4} \mathrm{~F}_{2}$ - new one-layer perovskite-like ferroelectric. Ferroelectrics 1978, 21, 423-434.

(48) Katayama, T.; Mo, S.; Maruyama, T.; Chikamatsu, A.; Hasegawa, T. Reactive solid phase epitaxy of layered aurivillius-type oxyfluorides $\mathrm{Bi}_{2} \mathrm{TiO}_{4} \mathrm{~F}_{2}$ using polyvinylidene fluoride. Dalton Trans. 2019, 48, 5425-5428.

(49) Morita, K.; Park, J.-S.; Kim, S.; Yasuoka, K.; Walsh, A. Crystal Engineering of $\mathrm{Bi}_{2} \mathrm{WO}_{6}$ to Polar Aurivillius-Phase Oxyhalides. J. Phys. Chem. C 2019, 123, 29155-29161.

(50) Larson, A. C.; Von Dreele, R. B. General Structure Analysis System (GSAS); Los Alamos National Laboratory Report, 2000.

(51) Toby, B. H. EXPGUI, a graphical user interface forGSAS. J. Appl. Crystallogr. 2001, 34, 210-213.

(52) Coelho, A. A. Indexing of powder diffraction patterns by iterative use of singular value decomposition. J. Appl. Crystallogr. 2003, 36, 86-95.

(53) Coelho, A. A. Topas Academic: General Profile and Structure Analysis Software for Powder Diffraction Data; Bruker AXS: Karlsruhe, Germany, 2012.

(54) McCabe, E. E.; Jones, I. P.; Zhang, D.; Hyatt, N. C.; Greaves, C. Crystal structure and electrical characterisation of $\mathrm{Bi}_{2} \mathrm{NbO}_{5} \mathrm{~F}$ : an Aurivillius oxide fluoride. J. Mater. Chem. 2007, 17, 1193-1200.

(55) McCabe, E. E.; Greaves, C. Structural and magnetic characterisation of $\mathrm{Bi}_{2} \mathrm{Sr}_{1.4} \mathrm{La}_{0.6} \mathrm{Nb}_{2} \mathrm{MnO}_{12}$ and its relationship to " $\mathrm{Bi}_{2} \mathrm{Sr}_{2} \mathrm{Nb}_{2} \mathrm{MnO}_{12}$ ". J. Mater. Chem. 2005, 15, 177-182.

(56) McCabe, E. E.; Greaves, C. Synthesis and Structural and Magnetic Characterization of Mixed Manganese-Coppern $=1$ Ruddlesden-Popper Phases. Chem. Mater. 2006, 18, 5774-5781.

(57) Campbell, B. J.; Stokes, H. T.; Tanner, D. E.; Hatch, D. M. ISODISPLACE: a web-based tool for exploring structural distortions. J. Appl. Crystallogr. 2006, 39, 607-614.

(58) Stokes, H. T.; Hatch, D. M.; Campbell, B. J. ISODISTORT, ISOTROPY Software Suite. www.iso.byu.edu.

(59) Hatch, D. M.; Stokes, H. T. Classification of octahedral tilting phases in the perovskite-like $A_{2} \mathrm{BX}_{4}$ structure. Phys. Rev. B: Condens. Matter Mater. Phys. 1987, 35, 8509-8516.

(60) Hatch, D. M.; Stokes, H. T.; Aleksandrov, K. S.; Misyul, S. V. Phase-transitions i the perovskite-like $A_{2} \mathrm{BX}_{4}$ structure. Phys. Rev. B: Condens. Matter Mater. Phys. 1989, 39, 9282-9288.

(61) Tuxworth, A. J.; McCabe, E. E.; Free, D. G.; Clark, S. J.; Evans, J. S. O. Structural Characterization and Physical Properties of the $\mathrm{New}$ Transition Metal Oxyselenide $\mathrm{La}_{2} \mathrm{O}_{2} \mathrm{ZnSe}_{2}$. Inorg. Chem. 2013, 52, 2078-2085.

(62) McCabe, E. E.; Stock, C.; Rodriguez, E. E.; Wills, A. S.; Taylor, J. W.; Evans, J. S. O. Weak spin interactions in Mott insulating $\mathrm{La}_{2} \mathrm{O}_{2} \mathrm{Fe}_{2} \mathrm{OSe}_{2}$. Phys. Rev. B: Condens. Matter Mater. Phys. 2014, 89, 100402.
(63) Brown, I. D.; Altermatt, D. Bond-valence parameters obtained from a systematic analysis of the Inorganic Crystal Structure Database. Acta Crystallogr., Sect. B: Struct. Sci. 1985, 41, 244-247.

(64) Brese, N. E.; O’Keeffe, M. Bond-valence parameters for solids. Acta Crystallogr., Sect. B: Struct. Sci. 1991, 47, 192-197.

(65) Newnham, R. E.; Wolfe, R. W.; Dorrian, J. F. Structural basis of ferroelectricity in the bismuth titanate family. Mater. Res. Bull. 1971, 6, 1029-1039.

(66) Wang, Y.; Tang, K.; Zhu, B.; Wang, D.; Hao, Q.; Wang, Y. Synthesis and structure of a new layered oxyfluoride $\mathrm{Sr}_{2} \mathrm{ScO}_{3} \mathrm{~F}$ with photocatalytic property. Mater. Res. Bull. 2015, 65, 42-46.

(67) Su, Y.; Tsujimoto, Y.; Matsushita, Y.; Yuan, Y.; He, J.; Yamaura, $K$. High-pressure synthesis, crystal structure and magnetic properties of $\mathrm{Sr}_{2} \mathrm{MnO}_{3} \mathrm{~F}$ : a new member of layered perovskite oxyfluorides. Inorg. Chem. 2016, 55, 2627-2633.

(68) Wang, J.; Shin, Y.; Paudel, J. R.; Grassi, J. D.; Sah, R. K.; Yang, W.; Karapetrova, E.; Zaidan, A.; Strocov, V. N.; Klewe, C.; Shafer, P.; Gray, A. X.; Rondinelli, J. M.; May, S. J. Strain-Induced Anion-Site Occupancy in Perovskite Oxyfluoride Films. Chem. Mater. 2021, 33, $1811-1820$.

(69) Attfield, J. P. Principles and applications of anion order in solid oxynitrides. Cryst. Growth Des. 2013, 13, 4623-4629.

(70) Salinas-Sanchez, A.; Garcia-Muñoz, J. L.; Rodriguez-Carvajal, J.; Saez-Puche, R.; Martinez, J. L. Structural characterisation of $R_{2} \mathrm{BaCuO}_{5}$ oxides by $\mathrm{X}$-ray and neutron diffraction. J. Solid State Chem. 1992, 100, 201-211.

(71) Brown, I. D. The Chemical Bond in Inorganic Chemistry; Oxford University Press, 2006; Vol. 12.

(72) Thompson, J. G.; Rae, A. D.; Bliznyuk, N.; Withers, R. L. Ordering of $\mathrm{Ce}^{3+} / \mathrm{Ce}^{4+}$ and interstitial oxygens in $\mathrm{CeTaO}_{4+x}(x=0.17)$ superstructures. J. Solid State Chem. 1999, 144, 240-246.

(73) Kurauchi, Y.; Katayama, T.; Chikamatsu, A.; Hasegawa, T. Two-dimensional fluorine distribution in a heavily distorted perovskite nickel oxyfluoride revealed by first-principles calculation. J. Phys. Chem. C 2019, 123, 31190-31195.

(74) Clark, L.; Oró-Solé, J.; Knight, K. S.; Fuertes, A.; Attfield, J. P. Thermally robustanion-chain rder in oxynitride perovskites. Chem. Mater. 2013, 25, 5004-5011.

(75) Withers, R. L.; Liu, Y.; Woodward, P.; Kim, Y.-I. Structurally frustrated polar nanoregions in $\mathrm{BaTaO}_{2} \mathrm{~N}$ and the relationship between its high dielectric permittivity and that of $\mathrm{BaTiO}_{3}$. Appl. Phys. Lett. 2008, 92, 102907.

(76) Fuertes, A. Nitride tuning of transition metal perovskites. APL Mater. 2020, 8, 020903.

(77) Yamaura, J.-I.; Maki, S.; Honda, T.; Matsui, Y.; Noviyanto, A.; Otomo, T.; Abe, H.; Murakami, Y.; Ohashi, N. Polar nano-region structure in the oxynitride perovskite $\mathrm{LaTiO}_{2} \mathrm{~N}$. Chem. Commun. 2020, 56, 1385-1388.

(78) Bousquet, E.; Dawber, M.; Stucki, N.; Lichtensteiger, C.; Hermet, P.; Gariglio, S.; Triscone, J.-M.; Ghosez, P. Improper ferroelectricity in perovskite oxide artificial superlattices. Nature $\mathbf{2 0 0 8}$ 452, 732-736.

(79) Teller, R. G.; Brazdil, J. F.; Grasselli, R. K.; Jorgensen, J. D. The structure of [gamma]-bismuth molybdate, Bi2MoO6, by powder neutron diffraction. Acta Crystallogr., Sect. C: Cryst. Struct. Commun. 1984, 40, 2001-2005.

(80) Theobald, F.; Laarif, A.; Hewat, A. W. The structure of koechlinite bismuth molybdate- a controversy resolved by neutron diffraction. Ferroelectrics 1984, 56, 219-237.

(81) Stone, G.; Ophus, C.; Birol, T.; Ciston, J.; Lee, C.-H.; Wang, K.; Fennie, C. J.; Schlom, D. G.; Alem, N.; Gopalan, V. Atomic scale imaging of competing polar states in a Ruddlesden-Popper layered oxide. Nat. Commun. 2016, 7, 12572. 